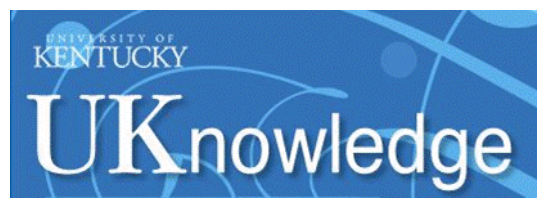

University of Kentucky

UKnowledge

\title{
2-7-2019
}

\section{Carboxylic Acids Accelerate Acidic Environment-Mediated Nanoceria Dissolution}

\author{
Robert A. Yokel \\ University of Kentucky, ryokel@email.uky.edu \\ Matthew L. Hancock \\ University of Kentucky, matthew.hancock@uky.edu \\ Eric A. Grulke \\ University of Kentucky, eric.grulke@uky.edu \\ Jason M. Unrine \\ University of Kentucky, jason.unrine@uky.edu
}

See next page for additional authors

Right click to open a feedback form in a new tab to let us know how this document benefits you. Follow this and additional works at: https://uknowledge.uky.edu/ps_facpub

Part of the Chemical Engineering Commons, Pharmacy and Pharmaceutical Sciences Commons, and the Soil Science Commons 


\section{Carboxylic Acids Accelerate Acidic Environment-Mediated Nanoceria Dissolution}

Digital Object Identifier (DOI)

https://doi.org/10.1080/17435390.2018.1553251

\section{Notes/Citation Information}

Published in Nanotoxicology, v. 13, issue 4.

Copyright @ 2018 Informa UK Limited

The copyright holder has granted the permission for posting the article here.

This is an Accepted Manuscript of an article published by Taylor \& Francis in Nanotoxicology on February 7, 2019, available online: http://www.tandfonline.com/10.1080/17435390.2018.1553251.

\section{Authors}

Robert A. Yokel, Matthew L. Hancock, Eric A. Grulke, Jason M. Unrine, Alan K. Dozier, and Uschi M.

Graham 


\section{Carboxylic Acids Accelerate Acidic Environment-Mediated Nanoceria Dissolution}

Robert A. Yokel ${ }^{\mathrm{a}^{*}}$, Matthew L Hancock ${ }^{\mathrm{b}}$, Eric A. Grulke ${ }^{\mathrm{b}}$, Jason M.

Unrine $^{\mathrm{c}}$, Alan K. Dozier ${ }^{\mathrm{d}}$, Uschi M. Grahamª,

${ }^{a}$ Pharmaceutical Sciences, ${ }^{\mathrm{b}}$ Chemical \& Materials Engineering, ${ }^{\mathrm{c}}$ Plant and Soil

Sciences, University of Kentucky, Lexington, $\mathrm{KY},{ }^{\mathrm{d}} \mathrm{CDC} / \mathrm{NIOSH}$, Cincinnati, $\mathrm{OH}$.

*Robert A. Yokel, Ph.D.

Department of Pharmaceutical Sciences

University of Kentucky Academic Medical Center

335 Todd (College of Pharmacy) Building

789 S. Limestone

Lexington, KY 40536-0596

phone: $859-257-4855$

fax: 859-257-7564

e-mail: ryokel@uky.edu 


\section{Carboxylic Acids Accelerate Acidic Environment-Mediated Nanoceria Dissolution}

Ligands that accelerate nanoceria dissolution may greatly affect its fate and effects. This project identified carboxylic acids that contribute to nanoceria dissolution in aqueous, acidic environments. Nanoceria has commercial and potential therapeutic applications. It biotransforms in vivo. Citric acid is commonly used to stabilize nanoceria during synthesis and in aqueous dispersions. In this study, citrate-stabilized nanoceria dispersions ( $\sim 4 \mathrm{~nm}$ average primary particle size) were placed in dialysis cassettes whose membranes would pass cerium salts but not nanoceria particles. The cassettes were immersed in isoosmotic baths containing carboxylic acids at $\mathrm{pH} 4.5$ at $37^{\circ} \mathrm{C}$, or select agents. Cerium atom material balances were conducted for the cassette and bath by sampling of each chamber and cerium quantitation by inductively coupled plasma mass spectrometry. Samples were also collected for high-resolution transmission electron microscopy observation of nanoceria size (cassette). In carboxylic acid solutions, nanoceria dissolution increased cerium concentration in the bath and decreased the nanoceria primary particle size in the cassette. In solutions of citric, malic, and lactic acid, and in the ammonium ion, $\sim 15 \mathrm{~nm}$ nanoceria agglomerates persisted. With other carboxylic acids, nanoceria agglomerates grew to $\sim 1$ micron. Nanoceria particles were stable in solutions containing citrate ( $\mathrm{pH}$ 7.4), water, or horseradish peroxidase i.e., the dissolution half-lives were very high. Extending these findings to in vivo and environmental systems, one would expect acidic environments containing carboxylic acids to degrade nanoceria by dissolution; two examples would be phagolysosomes and in the plant rhizosphere.

Keywords: carboxylic acids, electron microscopy, nanoceria, nanomaterial dissolution 


\section{Introduction}

Nanoceria (cerium oxide, $\mathrm{CeO}_{2}, \sim 1-100 \mathrm{~nm}$ ) is auto-catalytically redox active, cycling between $\mathrm{Ce}^{3+}$ and $\mathrm{Ce}^{4+}$ (Reed et al., 2014). Nanoceria is used as a diesel fuel additive (Dale et al., 2017), an abrasive in chemical mechanical planarization in integrated circuit manufacture (Feng et al., 2003), as a catalyst in storage batteries, and as a catalyst structural support (Senanayake et al., 2013). Nanoceria has therapeutic potential to treat conditions with an oxidative stress/inflammation component. Examples are cancer (Gao et al., 2014, Pesic et al., 2015), radiation damage (MaderoVisbal et al., 2012, Li et al., 2015), bacterial infection (Alpaslan et al., 2017) and sepsis (Selvaraj et al., 2015), wounds (Chigurupati et al., 2013), stroke-induced ischemia (Kim et al., 2012), and retinal degeneration (Wong and McGinnis, 2014).

Nanoceria is quite insoluble in circumneutral aqueous solutions. Solubility of 5 to 10 , 40 , and $<5000 \mathrm{~nm}$ ceria was extremely poor in water at neutral $\mathrm{pH}$ (Geraets et al., 2012). Dissolution of $7 \mathrm{~nm}$ ceria was reported to be insignificant after $72 \mathrm{~h}$ at $37{ }^{\circ} \mathrm{C}$ in physiological saline (pH 7.0) and artificial phagolysosomal fluid (pH 4.5) (He et al., 2010). Solubility of 5 and $10 \mathrm{~nm}$ ceria was null at $\mathrm{pH} 7.4$ and 0.2 and $0.3 \%$ after $24 \mathrm{~h}$ incubation in artificial lysosomal fluid (pH 5.5) at room temperature (Cho et al., 2012). After 28 days, $3 \%$ of 8 to $9 \mathrm{~nm}$ ceria dissolved in $\mathrm{pH} 4$ artificial soil solution and $<1 \%$ at pH 7 (Cornelis et al., 2011). Solubility of 10 to $200 \mathrm{~nm}$ ceria in water and DMEM + $10 \%$ fetal calf serum (FCS) after $24 \mathrm{~h}$ at $25{ }^{\circ} \mathrm{C}$ was $<0.001 \%$ (Wohlleben et al., 2013). Solubility after incubation for 28 days in water was $0.002 \%$; in DMEM/FCS, phagolysosomal simulant fluid, PBS, and fasted state simulated intestinal fluid $<$ $0.001 \%$; and $0.02 \%$ in $0.1 \mathrm{~N} \mathrm{HCl}$ (Keller et al., 2014). Solubilization was not seen after 28 days in phosphate-buffered saline or synthetic phagolysosomal simulant fluid, or 
after 7 days in fasted state simulated intestinal fluid. After 1 day in $0.1 \mathrm{~N} \mathrm{HCl}, 0.24 \%$ of the nanoceria dissolved (Molina et al., 2014). The log K solubility product of $\sim 5.6 \mathrm{~nm}$ ceria was found to be -59.3 in $0.01 \mathrm{M} \mathrm{NaClO}_{4}$ (Plakhova et al., 2016).

Poorly soluble nanomaterials are of concern in biological environments where they may persist for months, e. g., in mammals, or accumulate with repeated exposure (Laux et $a l ., 2017)$. The mass of cerium in the liver, spleen, and bone marrow (the three sites that accumulate the greatest amount of nanoceria) accounted for $45 \%$ of a single intravenous dose of $\sim 30 \mathrm{~nm}$ ceria ninety days later, compared to $60 \%$ of the dose after one day, demonstrating in vivo persistence (Yokel et al., 2012). Cerium concentrations in the liver and spleen five months after a single intravenous dose of $2.9 \mathrm{~nm}$ ceria were 12 and $116 \%$ of the concentrations after one day, respectively (Heckman et al., 2013). One hundred twenty days after an intravitreal injection of 3 to $4 \mathrm{~nm}$ ceria particles, $90 \%$ of the injected cerium remained in the eye and $70 \%$ was in the retina, resulting in estimated half-lives of 525 and 414 days, respectively (Wong et al., 2013). Nanoceria partially degraded in rat liver and spleen over 90 days after a single intravenous administration of $\sim 30 \mathrm{~nm}$ ceria, resulting in formation of 1 to $3 \mathrm{~nm}$, crystalline, ceriumcontaining particles that had more reduced $\left(\mathrm{Ce}^{3+}\right)$ surface cerium. This is thought to have occurred through a dissolution/re-crystallization process (Graham et al., 2014, Graham et al., 2017, Graham et al., 2018).

Dissolution of 32 and $78 \mathrm{~nm}$ ceria was shown in $\mathrm{pH} 1.65$, and less rapidly in 4.45 , but not in $\mathrm{pH} 7.45$ or 12.4 media over $120 \mathrm{~h}$, evidenced as increased cerium in the supernatant (Dahle et al., 2015). Twenty-five nm ceria incubated with citric and ascorbic acids or catechol as reducing agents at $\mathrm{pH} 5.5$ released cerium into the 
supernatant over 21 days (Rui et al., 2015). Citric acid on the surface of 4, 9, and $39 \mathrm{~nm}$ ceria stabilizes it against sedimentation due to agglomeration (Siriwardane, 2012).

Citric acid is used as a stabilizing agent for hydrothermal syntheses of nanoceria (e.g., (Masui et al., 2002, Zhang et al., 2007), and forms various coordination complexes with cerium (Bobtelsky and Graus, 1955, Leal, 1959, Zhang et al., 2007, Zhou et al., 2008).

In some systems, free radical sources are known to degrade nanomaterials. For example, single-walled carbon nanotubes degraded in the presence of peroxidases and hydrogen peroxide $\left(\mathrm{H}_{2} \mathrm{O}_{2}\right)$ (Allen et al., 2008, Kagan et al., 2010, Andón et al., 2013). Nanosilver dissolution rate correlated with the number of thiols per biomolecule (Marchioni et al., 2018). Other than the dissolution of nanoparticles that are considered quite soluble, such as manganese oxide, silver, and zinc oxide, the mechanisms of nanoparticle dissolution have not been well described.

The present study developed an acellular system to better understand nanoceria dissolution mechanisms, thereby modelling nanoceria's chemical fate during in vivo bioprocessing. Specifically, a nanoceria dispersion $(\sim 1 \mathrm{ml})$ in a Slide-A-Lyzer ${ }^{\mathrm{TM}}$ dialysis cassette with a $2 \mathrm{kD}$ MWCO regenerated cellulose membrane was immersed in a $200 \mathrm{ml}$ iso-osmotic bath containing carboxylic acids or select agents. In most cases, the bath $\mathrm{pH}$ was 4.5 (the $\mathrm{pH}$ of lysosomes), shown to mediate nanoceria dissolution (Dahle et al., 2015). Citric acid, known to complex cerium, and structural analogues of citric acid were included to identify the carboxylic acid chemistries that enhance nanoceria dissolution or stabilization. Adipic and pimelic acid were included because they appear to bind solely to the $\{100\}$ crystallite face of nanoceria (Grulke et al., 2014). Additional select agents were ammonium as a potential proton source; 
horseradish peroxidase (HRP) $+\mathrm{H}_{2} \mathrm{O}_{2}$, known to mediate carbon nanomaterial dissolution (Vlasova et al., 2016); and water. Bath and cassette samples were taken repeatedly for cerium analysis by inductively coupled plasma mass spectrometry (ICPMS) size and shape determination by high-resolution transmission electron microscopy (HRTEM). In some cases, electron energy loss spectroscopy (EELS) was used to determine valence of the dissolving nanoceria.

\section{Materials and Methods}

\section{Materials}

The chemicals, their sources, purity, and CAS \#s were: adipic acid, TCI, $\geq 99 \%, 124$ 04-9; ammonium nitrate, Fisher, ACS grade, 6484-52-2; citric acid monohydrate, Fisher, ACS grade, 5949-29-1; DL-3-hydroxybutyric acid sodium salt, Chem Impex Int'1 Inc., 100.30\%, 150-83-4 \& 306-31-0; DL-malic acid, Alfa Aesar, 98\%, 6915-15-7; glutaric acid, Acros organics, 99\%,110-94-1; hydrogen peroxide 3\% W/W, BDH chemicals, 7722-84-1; horseradish peroxide type II, Sigma, 150-250 U/mg, 9003-99-0; lactic acid, TCI, $\geq 85 \%, 50-21-5$; pimelic acid, Alfa Aesar, 98+\%, 111-16-0; sodium acetate, VWR, ACS grade, 127-09-3; sodium azide, Sigma, 99.8\%, 26628-22-8; sodium nitrate, BDH chemicals, ACS grade, 7631-99-4; succinic acid, TCI America, $\geq$ 99\%,110-15-6; and tricarballylic acid, Alfa Aesar, 98\%, 99-14-9. For electron microscopy, 200 mesh carbon support film on hexagonal copper square grids from Electron Microscopy Sciences were used. Pierce Biotechnology’s 2 kD MWCO SlideA-Lyzer ${ }^{\mathrm{TM}}$ dialysis cassettes were used.

\section{Nanoceria synthesis and characterization}


Polyhedral citrate-coated nanoceria crystallites were synthesized using a hydrothermal approach (Masui et al., 2002) and dialyzed 5 times, $12 \mathrm{~h}$ each, against iso-osmotic (110 $\mathrm{mM}$ ) citric acid at $\mathrm{pH} 7.4$ to remove any unreacted cerium salts and citrate coat the nanoceria to stabilize the dispersion. The nanoceria was stored at room temperature in the dark. It was sterilized by autoclaving prior to introduction into the cassettes. A sample $(500 \mu \mathrm{g}$ in $1 \mathrm{ml})$ of the citrate-coated nanoceria was dialyzed against $200 \mathrm{ml}$ water for $24 \mathrm{~h}$ with 3 changes of water, then dried, for HRTEM characeterization.

Nanoceria primary and hydrodynamic particle sizes were determined by TEM using a 200-keV field emission analytical transmission electron microscope (JEOL JEM-2010F; Tokyo, Japan) and dynamic light scattering (DLS) using a 90Plus Nanoparticle Size Distribution Analyzer (Brookhaven Instruments Corp., Holtsville, NY). Analytical hires TEM/STEM imaging was conducted to characterize its structure, surface nature, and d-spacing (distance between planes of atoms in the crystal structure). The surface and core $\mathrm{Ce}^{3+/} \mathrm{Ce}^{4+}$ ratios were determined from M4/M5 $\left(\mathrm{Ce}^{4+} \mathrm{Ce}^{3+}\right)$ peak heights after background subtraction and examined for $\mathrm{eV}$ shift of the Ce peaks and $\mathrm{O}$ peak. Similar EELS determinations were made of the nanoceria harvested from the cassette after its partial dissolution. Instruments included a JEOL 2100F field emission transmission and scanning transmission microscope (HRTEM/STEM) operated at $200 \mathrm{kV}$ with an analytic pole piece. Images were recorded using a Gatan Ultrascan 4k x 4k CCD camera. Data analysis and processing used Gatan Digital Micrograph software and Digiscan II. HRSTEM imaging was performed in combination with energy dispersive spectroscopy (EDS) and EELS analysis of select particles. Dark field imaging used a Gatan HAADF detector and Gatan GIF Tridiem ${ }^{\circledR}$ Filter. All HRSTEM images were acquired using an analytical probe with $0.17 \mathrm{~nm}$ resolution. An Oxford Aztec EDS 
system was used for select elemental mapping. The EELS measurements and trace lines were obtained using a $1 \mathrm{~nm}$ probe, an alpha of $12 \mathrm{mrad}$ and beta of $6 \mathrm{mrad}$. Analysis was obtained from core edge intensity acquired after background subtraction for different locations on select particles (center and rim) using an integration window ranging from $10-30 \mathrm{eV}$.

\section{Dialysis/dissolution system}

In a preliminary experiment, dialysis cassettes were loaded with $1 \mathrm{ml}$ of citrate-coated nanoceria in $110 \mathrm{mM}$ citric acid at $\mathrm{pH} 4.5$ and citrate-coated nanoceria in water at $\mathrm{pH}$ 4.5, and immersed in $400 \mathrm{ml}$ beakers containing $200 \mathrm{ml}$ of iso-osmotic sodium nitrate at $\mathrm{pH}$ 4.5. Over 8 weeks there was partial nanoceria dissolution, as reported in acidic media (Dahle et al., 2015). Dissolution was $\sim 55 \%$ greater in the presence of the citric acid loaded into the cassette. This led to the main study in which dialysis cassettes were loaded with $1 \mathrm{ml}$ of citrate-coated nanoceria (containing $~ 500 \mu \mathrm{g}$ cerium) in $1 \mathrm{ml}$ of iso-osmotic citric acid and immersed in $400 \mathrm{ml}$ beakers containing $200 \mathrm{ml}$ of an aqueous solution containing tested agents plus $0.02 \%$ sodium azide as a bacteriostatic and fungistatic agent. This nanoceria concentration was used by (Dahle et al., 2015). The tested solutions are shown in Table 1. Bath solutions, except water, were adjusted to iso-osmotic strength by sodium nitrate addition, using a Fiske Model 110 osmometer. Horseradish peroxidase ( 15 nmoles) was introduced into the cassette at $\mathrm{pH} 6.1$, the $\mathrm{pH}$ of its maximal activity. $\mathrm{H}_{2} \mathrm{O}_{2}$ was added to the bath at the beginning of the experiment and each time the bathing medium was sampled. The structures of the carboxylic acids are shown in Figure 1. 
The experimental set-up and sampling (described below) are illustrated in Figure 2. Each condition, except water, was studied in duplicate. The concentration of most ligands $(110 \mathrm{mM})$ was based on the concentration of citric acid to produce an isoosmotic solution, assuming total citric acid dissociation. Determination of the osmotic strength of $110 \mathrm{mM}$ citric acid revealed that it did not produce an iso-osmotic solution, presumably due to the lack of complete ionization (non-adherence to van't Hoff's law at this concentration). The acetic acid concentration $(20 \mathrm{mM})$ was used by (Dahle et al., 2015). The HRP- $\mathrm{H}_{2} \mathrm{O}_{2}$ condition was based on (Allen et al., 2008).

Cassette/beaker systems were sealed with Parafilm ${ }^{\circledR}$ and aluminum foil and housed in a rotary shaking incubator at $37{ }^{\circ} \mathrm{C}$ rotated at $60 \mathrm{rpm}$. The $\mathrm{HRP}-\mathrm{H}_{2} \mathrm{O}_{2}$ system was housed at $4{ }^{\circ} \mathrm{C}$, the temperature shown to degrade single walled carbon nanotubes (Allen et al., 2008).

Samples (Table 2) were acidified by addition of trace metal grade concentrated nitric acid ( $5 \mu 1$ to $75 \mu 1$ samples, $10 \mu 1$ to $1 \mathrm{ml}$ samples). Samples were spotted onto EM grids for TEM/STEM imaging. The bath and the cassette volumes were measured at the end of the experiment. The cassette was disassembled and its membranes and gasket immersed in $25 \mathrm{ml}$ of $5 \%$ nitric acid to determine residual cerium by ICP-MS.

The carboxylic acid concentrations used for the dissolution experiments were significantly higher than those expected for in vitro or in vivo environments. DLS was used to measure nanoceria size in systems containing carboxylic acid concentrations used in the bath study to three orders of magnitude smaller. Nanoceria $(1000 \mu \mathrm{g})$ was added to $2 \mathrm{ml}$ of iso-osmotic solution at $\mathrm{pH} 4.5$ containing $0.11,1.1,11$, or $110 \mathrm{mM}$ 
citric or malic acid, housed at room temperature. Nanoceria hydrodynamic particle size was determined immediately after its addition (time $=0)$ and repeatedly for 28 weeks (4704 h) by DLS, as described above. Samples were agitated before DLS measurement.

The diffusivity of cerium salts through the cassette membrane was measured to ensure that cerium salt transport through the membrane was much faster than the nanoceria dissolution rate. An aliquot of $480 \mu \mathrm{g}$ cerium ion in $1 \mathrm{~mL}$ water was placed in a cassette and dialyzed against $200 \mathrm{ml}$ of $110 \mathrm{mM}$ citric acid at $\mathrm{pH}$ 4.5. Bath samples were collected 1, 3, 6, 24, 96, 168, 336, and 504 h later for cerium quantitation. The data were fitted to an unsteady-state model for diffusion through the membrane to compute cerium ion diffusivity through the membrane and calculate the diffusion process halflife.

In a parallel study, particle size distributions in the bath solutions of Table 1 were measured repeatedly by DLS. Two $\mathrm{ml}$ of nanoceria dispersions were placed in DLS cuvettes. Particle size was repeatedly determined by DLS and occasional EM (Hancock et al., unpublished results).

\section{Cerium quantitation}

Samples containing nanoceria were digested with 2:1 $\mathrm{HNO}_{3}: \mathrm{H}_{2} \mathrm{O}_{2}$ in Teflon vessels in a CEM MARS Express microwave digestion system. Terbium was added as an internal standard, and analyzed compared to standards. Cerium was quantified by ICP-MS (Agilent 7500cx, Agilent Technologies, Inc., Santa Clara, CA) (Yokel et al., 2009).

\section{Data analysis}




\section{Apparent mechanisms of nanoceria dissolution}

Spherical solid particle degradation kinetics are usually described by first order or other similar nonlinear rate laws. A set of these models (zero-, first-, second-, and half-order in nanoceria concentration) were compared to the initial data. The results showed poor correspondence between data and any of the models. Rather, a surface-controlled dissolution model (Forryan et al., 2005) was found to provide good correspondence between experimentally-measured cerium mass in the bath and its prediction via the discrete material balance/dissolution rate model. This model gives the loss of atoms from a solid particle as directly proportional to its surface area. It was implemented using a population balance of nanoceria particles in the cassette plus the integrated kinetic rate equation that predicted the number of cerium atoms in a nanoparticle as a function of time. For this implementation of the surface-controlled model, an average particle size was assumed.

\section{Discrete material and population balances}

The sampling protocol (Table 2) shows that samples removed solution from the bath and cassette, removed cerium ions from the bath and cassette, and removed nanoceria from the cassette. In addition, there were water evaporative losses from the bath and solution transfers between the bath and cassette; these transfers are inferred from the initial and final cassette and bath volumes plus knowledge of the volume lost from the sampling protocol. We devised discrete balances of water volumes, cerium ions, and cerium atoms in nanoceria particles, along with a population balance for nanoceria particles in the cassette. The transport mechanisms of sample withdrawal and evaporation are shown in the cartoon of the experimental set-up (Figure 2). The balance assumptions and calculations are defined and described in (Grulke et al., submitted) 
Cassette phase: The surface-controlled dissolution model predicted the number of cerium atoms in a nanoparticle as a function of time, which is independent of the number of nanoparticles present in the cassette. The number of cerium atoms in the nanoceria solid phase in the cassette was computed by multiplying the number of nanoceria particles in the cassette by the number of cerium atoms per nanoparticle for any time interval. For the discrete balances, the number of cerium ions/nanoparticle was computed from the model for the starting and ending interval between sampling. Ion and solution flow between the cassette and bath was assumed to be in equilibrium. Cerium ions removed by sampling were also accounted for, but were essentially negligible except for a few experiments in which most of the nanoceria dissolved.

Bath phase: Water was lost by evaporation, which was averaged (as volume) across the entire experimental period. Cerium ion was lost due to sampling for ICP-MS and TEM/STEM analysis; this was accounted for at each sampling interval by the discrete volume and cerium ion balances for the bath.

\section{Results}

\section{Synthesized nanoceria}

Seventeen batches of nanoceria were prepared, all yielding similar products. One batch of nanoceria was used for this study. The average primary particle size by ImageJ analysis of 50 particles visualized by TEM was $\sim 4.2 \mathrm{~nm}$. Twenty-nine measurements of its hydrodynamic particle size distribution, taken 12 times over 9 months, showed that the nanoceria dispersion was stable. The primary agglomerate distribution was bimodal (Figure 3a), with peaks at $\sim 14 \mathrm{~nm}(\geq 95 \%$ based on surface area) and $\sim 33 \mathrm{~nm}$. All 
twenty-nine measurements gave similar agglomerate distributions, showing that the nanoceria dispersion was stable at these storage conditions. Autoclaving did not significantly change the distribution mean sizes. Preparation and purification included dialysis against $110 \mathrm{mM}$ citric acid to remove reaction components not incorporated into the synthesized nanoceria, a step not previously reported in the many reports of nanoceria synthesis. This results in citrate-coated nanoceria. When subsequently dialyzed against water for $24 \mathrm{~h}$, nine months after its synthesis and purification by dialysis against citric acid, only $\sim 0.1 \%$ of the cerium in the nanoceria diffused into the water. TEM/STEM data showed crystal morphology, lattice, and d-spacing consistent with nanoceria. Figure $3 \mathrm{~b}$ shows a typical agglomerate consisting of a typical number and arrangement of nanoceria crystallites. Figure $3 \mathrm{c}$ shows a single nanoceria crystallite prior to dissolution. It has sharp edges in profile. The nanoceria surface has a predominance of $\mathrm{Ce}^{3+}$. Panel d shows nanoceria d-spacings of $0.54 \mathrm{~nm}$, characteristic for nanoceria (Kurian and Kunjachan, 2014). Results of other physicochemical characterizations of this nanomaterial will be included in a separate publication.

The dissolution process model relates the dissolution rate directly to the surface area of the particle. Obviously, a larger particle has greater surface area than a smaller one. However, the surface area per unit volume for spheroidal particles scales as 6/D $\left(\mathrm{nm}^{2} / \mathrm{nm}^{3}\right)$, so smaller nanoparticles loose mass at higher rates per unit volume. As nanoceria particle size decreases, surface $\mathrm{Ce}^{3+}$ increases, leading to lattice strain and increased solubility (Grulke et al., 2014). TEM/STEM images of nanoceria particles were used to verify that dissolution occurred. It was easier to detect dissolution by imaging larger particles, such as the one shown in Figure $3 \mathrm{c}$. This particle has a diameter of $\sim 7.15 \mathrm{~nm}$ after 1344 hours of dissolution, but has lost the sharp edges and 
corners of the starting material. Using this particle and its size at 1344 hours of dissolution as an example, the dissolution rate model was used to estimate the original particle size $(7.53 \mathrm{~nm})$ and number of cerium atoms/particle (5645). At 1344 hours, the particle would have 4834 cerium atoms and an average size of $7.15 \mathrm{~nm}$, losing about $15 \%$ of its mass. Nanoceria particles of the average size, $4.2 \mathrm{~nm}$, would have lost $25 \%$ of their mass over the same time.

\section{Diffusivity of cerium salts through the cassette membrane}

An unsteady state diffusion experiment using cerium nitrate was conducted to determine the diffusivity of cerium and the half-life of diffusion through the membrane. Cerium diffusivity through the membrane was $4.4 \times 10^{-12} \mathrm{~m}^{2} / \mathrm{s}$; the half-life was $12.5 \mathrm{~h}$. A second experiment replicated this result. By direct comparison of the process half-lives, cerium ion diffusion through the membrane is $>60$ times faster than any of the measured nanoceria rates as represented by half-lives, implying that cerium ion concentrations between the cassette and bath were at steady-state relative to the dissolution rate. The rate of cerium ion diffusion through the $2 \mathrm{kD}$ membrane and equilibrium in the $200 \mathrm{ml}$ bathing medium did not appreciably influence the appearance of cerium in the bathing medium as nanoceria dissolved.

\section{Cerium mass in the bath}

Mass balance calculations were conducted incorporating the results of the cerium concentration of the nanoceria loaded into the cassette and the mean of the lower, the higher, and the average of each of the 7 pair of results obtained throughout the study. The results were 461,613 , and $532 \mu \mathrm{g}$, respectively. The overall mean $(532 \mu \mathrm{g})$ provided the best overall material balance results when compared to the mass of cerium 
in the cassette solution and the cassette at the end of the experiment, and was used for the mass balance and rate constant determinations. Representative model fits for three examples are shown and described in detail in (Grulke et al., submitted).

Figure 4 shows plots of the percentage of nanoceria dissolved as a function of time for 12 bath solution additives. The data are shown for two replicate experiments. The plots are ordered (left to right, top to bottom) to correspond with the dissolution half-lives (Table 3). Table 3 also lists the average diameters for the nanoceria particles after 28 weeks of dissolution, based on the surface-controlled dissolution predictions. The HRP and water conditions have similar, very large, half-lives, so the water results are not presented in Figure 4. The ammonium ion bath half-time for dissolution was a factor of two higher than those of any carboxylic acid. Lactic acid has the shortest dissolution half-life. The model predicts complete dissolution in $3024 \mathrm{~h}$. The plot for the lactic acid system (Figure 4) is consistent with this prediction, as it reaches a maximum (100\%) at $\sim 3,000 \mathrm{~h}$. The cerium material balance was most accurate for the lactic acid system: since dissolution was rapid, there were fewer cerium and nanoceria losses due to sampling.

Table 3 also shows the average nanoceria particle diameter as predicted from the dissolution rate model. The starting value, $4.2 \mathrm{~nm}$, was established from TEM particle size distributions (above). For reference, the expected nanoceria particle diameter was $3.4 \mathrm{~nm}$ at the half-life conditions.

\section{Effects of lower carboxylic acid concentration on nanoceria dissolution}


The addition of $1000 \mu \mathrm{g}$ nanoceria to $2 \mathrm{ml}$ of iso-osmotic solution at $\mathrm{pH} 4.5$ containing $0.11,1.1,11$, or $110 \mathrm{mM}$ citric or malic acid showed an initial reduction of nanoceria size over several hundred $\mathrm{h}$ and continued reduction for 28 weeks in 11 to $110 \mathrm{mM}$ citric and 0.11 to $110 \mathrm{mM}$ lactic acid (Figure 5). Particle settling was not observed. In the presence of two $\mathrm{ml}$ of $11 \mathrm{mM}$ citric or malic acid, the molar ratio of carboxylic acid to cerium in $1000 \mu \mathrm{g}$ nanoceria is 3 , whereas the ratio for $200 \mathrm{ml}$ of $110 \mathrm{mM}$ carboxylic acid to $500 \mu \mathrm{g}$ cerium in nanoceria (as in the cassette experiments) is $6 \times 10^{3}$. These results suggest the dissolution of nanoceria in the dialysis system is not an artifact of the excess of carboxylic acid compared to nanoceria, and extends down to equimolar carboxylic acid to nanoceria concentrations.

\section{Morphology, size, valence, and agglomeration of nanoceria in the cassettes}

Transformation of nanoceria in the cassettes occurred over three phases. Phase 1 findings 4 weeks after initiation of dialysis/dissolution are characterized by secondary nanoceria agglomerates interlinked to various degrees into superstructures (tertiary structures, characterized by accumulation of many nanoceria secondary structure agglomerates into architectures up to micron scale made up of teeming, interconnecting, agglomerates, associated in ligand-dependent arrangements). In many experimental conditions these persisted through Phases 2 and 3. Dissolution occurred first at crystal corners and edges, resulting in particle rounding (Figure 6) and some decrease of primary particle size in $\mathrm{pH} 4.5$, but not $\mathrm{pH} \sim 6$, conditions. Nanoceria dissolution did not result in a phase transformation, e.g., recrystallization. In the presence of some ligands, nanoceria dissolution revealed fresh particle surface layers (due to ion shedding) that appeared to promote self-assemblies of nanoceria particles in superstructures (Figure 7). In Phase 2, twelve weeks after initiation of 
dialysis/dissolution, there was a clear difference in solubility and primary and secondary particle size among the experimental conditions from Phase 1, with ligand-selective superstructure destruction and increased distance between superstructures. In Phase 3 equilibrium was reached, evidenced by little reduction in the primary particle size from Phase 2, in which the agglomerates developed a skeletal appearance, concurrent with no change in cerium concentration in the bathing medium. The following describes the observations of these phases in more detail.

Phase 1 findings were characterized by formation of tertiary superstructures and evidence of $\mathrm{pH}$-dependent nanoceria dissolution (Figure 7). The tertiary superstructures are susceptible to external forces and can be broken up into the agglomerate units. In contrast, the secondary agglomerates, which consist of closely arranged primary nanoceria crystallites, were structurally stable. The secondary agglomerates formed during nanoceria synthesis; superstructures formed during Phase 1 of carboxylic acid medium-dependent nanoceria dissolution (Figure 7 left column). Superstructures were seen in the presence of all ligands (Figure 7), but the degree of superstructure formation was strongly ligand dependent, ranging up to micron size in the presence of tricarballylic, hydroxybutyric, pimelic, acetic, and adipic acids (Figure $7 \mathrm{j}, \mathrm{m}, \mathrm{p}, \mathrm{s}$, and y), with very little superstructure formation with succinic, malic, and lactic acids (Figure $7 \mathrm{ab}$, ae, and ah). At $\mathrm{pH} \sim 6$ (water) there was no formation of tertiary superstructures or reduction in primary or secondary (agglomerate) particle size.

Phase 2 findings are characterized by lack of significant change in the tertiary superstructure from Phase 1, but obvious presence of nanoceria dissolution, resulting in rounding of nanoceria crystallite edges under all carboxylic acid conditions at $\mathrm{pH} 4.5$. 
For example, in the presence of citric acid (Figure $7 \mathrm{w}$ ) nanoceria's secondary structure persisted into Phase 2 (overall size and shape of agglomerates), but the primary crystal particles bound to each other in the agglomerates changed due to dissolution. This was evidenced by the reduction of primary particle size, and to a lesser degree reduction of the secondary structure (agglomerate) size, creating much larger voids between primary particles, that gave the secondary structures a skeletal appearance. This was observed for all ligands, with some variability among the ligands. Ligand type did not alter the crystallinity of the primary particles as they dissolved within the secondary structure, but led to smaller and more rounded nanoceria. In general, the secondary structures did not collapse or reorganize as a result of the initial dissolution process. However, some carboxylic acids (malic and lactic) caused a much greater skeletal formation in the agglomerates, due to more rapid nanoceria dissolution. This resulted in significant void formation between primary nanoceria particles. This was observed to a lesser extent for other carboxylic acids (Figure 7). The reduction of primary particle size was associated with the increasing concentration of cerium in the bath (Figure 4).

In Phase 3, which represents the late dissolution stage (Figure 7 column 3) at 28 weeks, most superstructures were gone and there was a significant reduction in the primary nanoceria and secondary agglomerate size; HRP being the only exception (Figure 7 ac). Particle size reduction correlated well with dissolution half-lives (Table 3). The citric acid example shows isolated residual small porous agglomerates (Figure $7 \mathrm{x}$ ) while the lactic acid example shows minute crystallites (individual nanoceria with reduced size compared to the starting material), suggesting agglomerate disintegration (Figure 7 aj). Comparison among images (Figure 7, column 3) shows that agglomerates were no longer closely packed, but rather adopt a skeletal appearance due to the greatly 
increased void space caused by dissolution and size reduction of the primary nanoceria. In the presence of glutaric (Figure 7 i), tricarballylic (Figure 7 1), hydroxybutyric (Figure 7 o), pimelic (Figure 7 r), acetic (Figure 7 u), citric (Figure 7 x), adipic (Figure 7 aa), and succinic (Figure 7 ad) acids, dissolution observed in Phase 3 resulted in isolated occurrences of skeletal agglomerates, but superstructures were completely gone. In the presence of malic (Figure 7 ag) and lactic (Figure 7 aj) acids, skeletal agglomerates were further destroyed, such that only isolated primary nanoceria crystallites remained, with most having smaller than original size and rounding along edges due to ion shedding from the surface layers.

EELS analyses were performed on the as-synthesized and partially-dissolved nanoceria to determine if dissolution initiated and progressed along the nanoceria particle surface, affecting its surface valence (Figure 8). The nanoceria surfaces after citric acid exposure were relatively enriched in $\mathrm{Ce}^{3+}$, the antioxidant valence state, determined by the cerium M4 M5 peak heights in comparison with as-synthesized nanoceria, while nanoceria core regions were less affected (Figure 8). These results were observed for all ligands. Continued dissolution along the nanoceria surfaces causes defect formations in the crystallite surface layers, including oxygen vacancies which affect nanoceria's electronic and chemical surface properties. This is reflected in the observed increased M5 vs. M4 peak height (Figure 8). Oxygen defect density increased along the destabilized dissolving nanoceria surfaces.

\section{Discussion and Conclusions}

Nanoceria prepared by the method utilized in this project appears to be stable in aqueous solution containing $110 \mathrm{mM}$ citric acid at $\mathrm{pH} 7.4$ for at least 9 months, shown 
by consistent particle size over that time, when autoclaved, and dialyzed against water. Carboxylic acids (Taguchi et al., 2009, Grulke et al., 2014), imine-containing polymers (Kitsou et al., 2017), and surfactants are known to stabilize nanoceria particles during synthesis. In contrast, when exposed to $\mathrm{pH} 4.5$ in the presence of 11 or $110 \mathrm{mM}$ citric acid; $20 \mathrm{mM}$ acetic acid; 0.11 to $110 \mathrm{mM}$ malic acid; $110 \mathrm{mM}$ adipic, glutaric, hydroxybutyric, lactic, pimelic, succinic, or tricarballylic acid; or $20 \mathrm{mM}$ ammonium, citrate-coated nanoceria underwent partial dissolution over time. Dissolution did not occur in water or $\mathrm{HRP}+\mathrm{H}_{2} \mathrm{O}_{2}$ at $\sim \mathrm{pH}$ 6. The latter condition degrades carbon nanotubes. These results demonstrate the role of the acidic environment in nanoceria dissolution, as shown (Dahle et al., 2015). The absence of nanoceria dissolution in HRP $+\mathrm{H}_{2} \mathrm{O}_{2}$ suggests a mechanism of nanoceria dissolution different from carbon-based nanomaterial biodegradation, which is mediated by enzymatic catalysis, presumably involving a redox reaction.

In the presence of carboxylic acids at $\mathrm{pH} 4.5$, electron micrographic images showed initial dissolution at the corners of the polyhedral (predominantly $\{111\}$ and $\{100\}$ faces) polycrystalline nanoceria, the regions of highest instability, followed by primary particle size reduction and rounding over time. Based on TEM results, the absence/presence of nanoceria particles $<2 \mathrm{~nm}$ cannot be addressed, therefore the possibility that primary particles totally dissolved cannot be assured. Carboxylic acid addition accelerated the nanoceria dissolution rate. This is in contrast to nanoceria stability prepared in citric acid to efficiently coat its surface, cease particle growth during production, and prevent agglomeration. Citrate-coated nanoceria was stable at $\mathrm{pH} 7.4$ in iso-osmotic citrate for months. The results suggest the citric acid coating is susceptible to desorption in an acidic environment. Carboxylic acids may facilitate 
dissolution by providing a ligand to complex the cerium ion released during nanoceria dissolution, preventing agglomeration in some cases and promoting superstructure formation in others. Lactic, malic, succinic, adipic, and citric acid produced the lowest dissolution half-times. Lactic, malic, and citric acids gave nanoceria agglomerates that did not increase their hydrodynamic diameters with dissolution time.

Considering the effect of citric, malic, and lactic acids on the relative rates of nanoceria dissolution and their ability to maintain nanoceria's secondary structure and prevent formation of micron sized tertiary structures as the nanoceria dissolved, they were more effective than the other carboxylic acids to solubilize and stabilize nanoceria. The National Institute of Standards and Technology Critically Selected Stability Constants of Metal Complexes database includes reports of the $\log \mathrm{K}_{1}$ and $\beta_{\mathrm{n}}$ for $\mathrm{Ce}^{3+}$ and $\mathrm{Ce}^{4+}$ where $\mathrm{K}$ is the stepwise formation/stability/association constant of the cerium-ligand coordination complex and $\beta_{\mathrm{n}}$ is the cumulative constant of the $\mathrm{n}$ stepwise coordination complexes. Values from that source for the carboxylic acids of the present study are in the Supplementary Materials (Table S1). The carboxylic acids that have the greater ability to accelerate nanoceria dissolution generally better stabilize it (Figure S1).

The coordination bonds that form between citrate and lanthanide series metals (lanthanum, cerium, and gadolinium) (Bobtelsky and Graus, 1955, Baggio et al., 2005, Zhou et al., 2008, Chen et al., 2012, Heller et al., 2012) involve carboxylate and hydroxyl groups, presumably mediating the acceleration of nanoceria dissolution and maintenance of nanoceria stability at $\mathrm{pH}$ 4.5. This is supported by density functional theory analyses, described in (Grulke et al., submitted). Adipic and pimelic acids accelerated nanoceria dissolution, consistent with their selective binding to the $\{100\}$ 
crystallite face of nanoceria and presence of two carboxyl groups that could form a coordination complex with cerium (Taguchi et al., 2009). Dicarboxylic acids with longer chain lengths adsorbed to nanoceria surfaces, but generated membrane-like protective coatings on the particles (Taguchi et al., 2009).

Small cerium-containing coordination complexes were able to diffuse through the $\sim 2$ $\mathrm{nm}$ pores of the cassette membrane into the bathing medium. At the levels of cerium ligands in these experiments, the cerium salts do not appear to be present above their solubility limits. Cerium citrate is quite insoluble (Table S1). The only identified report of a value reported its solubility to be 3.02 and $6.40 \mathrm{~g} / \mathrm{L}$ in $\mathrm{H}_{2} \mathrm{O}$ at 20 and $90^{\circ}$, respectively (Ezerskaya and Cherches, 1973), greater than the cerium concentration if all of the nanoceria in the dialysis cassette equally distributed throughout the dialysis/dissolution system $(\sim 0.00250 \mathrm{~g} / \mathrm{L})$. Reported solubility products of the other ligands of this study are lower than the citric acid solubility product (Table S1).

The experimental system of this study does not totally model the complex in vivo environment that mediates nanoceria dissolution and reorganization. However, the results of this study clearly show the primary role of $\mathrm{pH}$ mediating nanoceria dissolution, and the release of cerium salts that could be a key step of nanoceria bioprocessing in vivo. The primary difference is the lack of phosphate-containing ligands. This is being investigated in ongoing work, as well as the biological response to the partially degraded, and probably ligand-coated, nanoceria.

The formation of carboxylic acid-cerium complexes after nanoceria dissolution may enable redistribution of cerium released from nanoceria dissolution within organisms 
and uptake into plant roots, similar to the role of citrate to release iron from the low-pH environment of endosomes (Arbab et al., 2005). This may explain the organ-specific bioprocessing of ceria (Graham et al., 2018). Ligands that enable nanoceria dissolution in acidic environments may greatly affect nanoceria's fate (dissolution rate and size as well as transport phenomena through ion release).

The carboxylic acids that accelerate nanoceria dissolution are biologically relevant. Lactic acid is a product of anaerobic glycolysis and anaerobic metabolism. Citric, malic, and succinic acids are intermediates in the tricarboxylic acid cycle. Acetic acid is a product of free fatty acid and alcohol metabolism. The presence and concentration of these small carboxylic acids in conjunction with acidic $\mathrm{pH}$ may influence nanoceria dissolution and stabilization of released cerium ion in vivo. Although the concentration of most of these carboxylic acids in mammalian cells has apparently not been determined, the interstitial fluid total organic anion concentration is $\sim 5 \mathrm{mEq} / \mathrm{l}$, citric acid can reach $10 \mathrm{mM}$ in some cells, and muscle lactate can reach $\sim 30 \mathrm{mM}$ during intense exercise (Legiša and Kidrič, 1989, Bangsbo et al., 1990). Their constant turnover provides a continual source of carboxylic acids to in vivo nanoceria.

Citric acid has been shown to accelerate the dissolution of other metal oxide nanomaterials. The rate of iron oxide nanoparticle dissolution in the presence of $20 \mathrm{mM}$ citric acid was greater at $\mathrm{pH} 4.5$ than 5.5 than 7.0 to 7.2 (Arbab et al., 2005, Soenen et al., 2010, Hoskins et al., 2012), but was not seen with acetate under the same condition (Arbab et al., 2005). $1.56 \mathrm{mM}$ citric acid, at a starting $\mathrm{pH}$ of 5, greatly increased the dissolution of $\mathrm{ZnO}$ and $\mathrm{CuO}$ nanoparticles (Zabrieski et al., 2015). Nanotitania is another metal oxide nanomaterial generally considered to be quite inert. A sodium 
citrate $\mathrm{pH} 4.5$ buffer, mimicking the lysosomal compartment in the present study, degraded anatase nanotitania over $96 \mathrm{~h}$ to a greater extent than the rutile form. Neither degraded in water or DMEM cell culture medium at pH 7 (De Matteis et al., 2016).

During dissolution nanoceria underwent three temporal phases, including selfassociation into tertiary structures (superstructures), and demonstrable reduction of primary particle size. The formation of tertiary superstructures in Phase 1 provides insight into the interaction of nanoceria particles in different environmental conditions. Superstructures occur because the nanoceria agglomerates (secondary structures) experience a surface leaching (ion shedding) effect during exposure to acidic environments containing carboxylic acids. The surface modification promotes the attraction of secondary structures (nanoceria agglomerates) to link into superstructures. The bonding type between these agglomerates is rather weak since the superstructures are susceptible to mechanical breakage or other external forces (electron beam). However, the individual agglomerates, which consist of closely arranged primary nanoceria crystallites, are structurally stable. HRTEM revealed that the type and degree (intensity) of superstructure formation is ligand-dependent. This may be related to the unique agglomerate assemblies of nanoceria discovered previously in different organs after its intravenous administration, such as in the liver vs. the spleen where nanoceria undergoes organ-specific bioprocessing (Graham et al., 2018). Organ-specific bioprocessing and assemblies of nanoceria may depend on available ligand types and concentrations that modify surface functional properties of the nanoceria after uptake, such as particle charge and ability to complex with available organ-specific molecules. Depending on the environmental concentrations and chemistries of ligands in different organs, their role in nanoceria dissolution may vary, which may have a strong influence 
on nanoceria or ionic cerium transport mechanisms and ability to translocate to other regions in the body.

A result of the increased distance between primary particles in the secondary nanoceria structures (agglomerates) (Figure 7, particularly during Phase 2), which shows the ligand-depending tendency of dissolving agglomerates to form skeletal structures, is a general surface area increase. This is due to the fact that the smaller nanoceria inside the agglomerates contribute to a higher surface area per volume and also help form more void spaces which reveal more nanoceria surface to the surrounding solvent medium. Nanoceria dissolution is controlled/driven by kinetic processes, quantified by the calculated rate constants (Grulke et al., submitted) that result in variable dissolution half-lives (Table 3).

Phase 3 is characterized by equilibrium conditions, as shown in Figure 4 for glutaric, citric, malic, and lactic acids after $\sim 4000 \mathrm{~h}$. For those ligands we also observed in HRTEM some remaining nanoceria crystallites, albeit with significantly reduced size and strong surface rounding effects (Figure $7 \mathrm{i}, \mathrm{u}, \mathrm{ad}$, and aj). There is no evidence from our observations that cerium ions contributed to nanoceria formation, e.g. it appears that nanoceria dissolution occurred in the absence of nanoceria precipitation. This is based on HRTEM investigation that indicated that all nanoceria correspond to the starting materials and the physical difference is due to surface shedding of ions and not recrystallization or reformation. In the current study the cassette experiments that resulted in the partial dissolution of the nanoceria (ligand-dependent process) did not generate conditions that provide supersaturation of cerium ions. No Ostwald ripening effects were observed in this study where original nanoceria crystals grow due to 
surface attachment of dissolved ions that come from dissolving nanoceria in the cassette. However, the shedding of ions from nanoceria that are concentrated in macrophages in vivo may provide such supersaturation conditions and this would explain why we observed a dissolution of nanoceria that is accompanied by regrowth of nanoceria or reprecipitation of other cerium phases (cerium phosphate) (Graham et al., 2018).

In summary, acidic environments, as found in phagolysosomes, may degrade nanoceria by dissolution, accelerated by carboxylic acids. Carboxylic acids may coat the nanoceria to form a "corona", which would be expected to profoundly influence nanoceria's fate and cellular response. Nanoceria coating, dissolution, and coordinate complex formation with carboxylic acids can profoundly influence nanoceria's fate and effects.

\section{Acknowledgements}

The authors gratefully acknowledge Marsha L. Ensor, Shristi Shrestha, and Tanner Wellman for their excellent contributions to this research.

\section{Funding details}

This work was supported by NIH under Grant 1R01GM109195. The findings and conclusions in this report are those of the authors and do not necessarily represent the official position of the National Institute for Occupational Safety and Health, Centers for Disease Control and Prevention. 


\section{References}

Allen, B.L., Kichambare, P.D., Gou, P., Vlasova, I.I., Kapralov, A.A., Konduru, N., Kagan, V.E. \& Star, A., 2008. Biodegradation of single-walled carbon nanotubes through enzymatic catalysis. Nano Lett., 8, 3899-3903.

Alpaslan, E., Geilich, B.M., Yazici, H. \& Webster, T.J., 2017. pH-controlled cerium oxide nanoparticle inhibition of both gram-positive and gram-negative bacteria growth. Scientific Reports, 7, 45859.

Andón, F.T., Kapralov, A.A., Yanamala, N., Feng, W., Baygan, A., Chambers, B.J., Hultenby, K., Ye, F., Toprak, M.S., Brandner, B.D., Fornara, A., KleinSeetharaman, J., Kotchey, G.P., Star, A., Shvedova, A.A., Fadeel, B. \& Kagan, V.E., 2013. Biodegradation of single-walled carbon nanotubes by eosinophil peroxidase. Small, 9, 2721-2729.

Arbab, A.S., Wilson, L.B., Ashari, P., Jordan, E.K., Lewis, B.K. \& Frank, J.A., 2005. A model of lysosomal metabolism of dextran coated superparamagnetic iron oxide (SPIO) nanoparticles: implications for cellular magnetic resonance imaging. NMR Biomed., 18, 383-389.

Baggio, R., Calvo, R., Garland, M.T., Pena, O., Perec, M. \& Rizzi, A., 2005. Gadolinium and neodymium citrates: Evidence for weak ferromagnetic exchange between gadolinium(III) cations. Inorg Chem, 44, 8979-8987.

Bangsbo, J., Gollnick, P.D., Graham, T.E., Juel, C., Kiens, B., Mizuno, M. \& Saltin, B., 1990. Anaerobic energy production and $\mathrm{O}_{2}$ deficit-debt relationship during exhaustive exercise in humans. J Physiol, 422, 539-59.

Bobtelsky, M. \& Graus, B., 1955. Cerous citrate complexes, their composition, structure, and behavior. J Am Chem Soc, 77, 1990-3.

Chen, M.-L., Gao, S. \& Zhou, Z.-H., 2012. Isolations and characterization of highly water-soluble dimeric lanthanide citrate and malate with ethylenediaminetetraacetate. Dalton Trans, 41, 1202-1209.

Chigurupati, S., Mughal, M.R., Okun, E., Das, S., Kumar, A., Mccaffery, M., Seal, S. \& Mattson, M.P., 2013. Effects of cerium oxide nanoparticles on the growth of keratinocytes, fibroblasts and vascular endothelial cells in cutaneous wound healing. Biomaterials, 34, 2194-2201.

Cho, W.-S., Duffin, R., Thielbeer, F., Bradley, M., Megson, I.L., Macnee, W., Poland, C.A., Tran, C.L. \& Donaldson, K., 2012. Zeta potential and solubility to toxic ions as mechanisms of lung inflammation caused by metal/metal oxide nanoparticles. Toxicol Sci, 126, 469-477.

Cornelis, G., Ryan, B., Mclaughlin, M.J., Kirby, J.K., Beak, D. \& Chittleborough, D., 2011. Solubility and batch retention of $\mathrm{CeO}_{2}$ nanoparticles in soils. Environ Sci Technol, 45, 2777-2782.

Dahle, J.T., Livi, K. \& Arai, Y., 2015. Effects of $\mathrm{pH}$ and phosphate on $\mathrm{CeO}_{2}$ nanoparticle dissolution. Chemosphere, 119, 1365-1371.

Dale, J.G., Cox, S.S., Vance, M.E., Marr, L.C. \& Hochella, M.F., 2017. Transformation of cerium oxide nanoparticles from a diesel fuel additive during combustion in a diesel engine. Environ Sci Technol, 51, 1973-1980.

De Matteis, V., Cascione, M., Brunetti, V., Toma, C.C. \& Rinaldi, R., 2016. Toxicity assessment of anatase and rutile titanium dioxide nanoparticles: The role of degradation in different $\mathrm{pH}$ conditions and light exposure. Toxicol In Vitro, 37, 201-210.

Ezerskaya, T.P. \& Cherches, K.A., 1973. [Solubility of citrate complex acids of ceriumgroup lanthanoids in water]. Izv Vyssh Ucheb Zaved, Khim Khim Tekhnol, 16, 648. 
Feng, X., Her, Y.-S., Zhang, W.L., Davis, J., Oswald, E., Lu, J., Bryg, V., Freeman, S. \& Gnizak, D., 2003. $\mathrm{CeO}_{2}$ particles for chemical mechanical planarization. Materials Res Soc Symp Proc 767, 173-183.

Forryan, C.L., Klymenko, O.V., Brennan, C.M. \& Compton, R.G., 2005. Reactions at the solid-liquid interface: surface-controlled dissolution of solid particles. The dissolution of potassium bicarbonate in dimethylformamide. $J$ Phys Chem B 109, 2862-2872.

Gao, Y., Ma, J.-L., Chen, K. \& Gao, F., 2014. Cerium oxide nanoparticles in cancer. Onco Targets Ther, 7, 835-40.

Geraets, L., Oomen, A.G., Schroeter, J.D., Coleman, V.A. \& Cassee, F.R., 2012. Tissue distribution of inhaled micro- and nano-sized cerium oxide particles in rats: Results from a 28-day exposure study. Toxicol Sci, 127, 463-473.

Graham, U.M., Jacobs, G., Yokel, R.A., Davis, B.H., Dozier, A.K., Birch, M.E., Tseng, M.T., Oberdörster, G., Elder, A. \& Delouise, L., 2017. From dose to response: In vivo nanoparticle processing and potential toxicity. In L. Tran, M.A. Bañares \& R. Rallo (eds.) Modelling the Toxicity of Nanoparticles. Cham, Switzerland: Springer, 71-100.

Graham, U.M., Tseng, M.T., Jasinski, J.B., Yokel, R.A., Unrine, J.M., Davis, B.H., Dozier, A.K., Hardas, S.S., Sultana, R., Grulke, E. \& Butterfield, D.A., 2014. In vivo processing of ceria nanoparticles inside liver: Impact on free radical scavenging activity and oxidative stress. ChemPlusChem, 79, 1083-1088.

Graham, U.M., Yokel, R.A., Dozier, A.K., Drummy, L., Mahalingam, K., Tseng, M.T., Birch, E. \& Fernback, J., 2018. Analytical high-resolution electron microscopy reveals organ specific nanoceria bioprocessing. Toxicol Pathol, 46, 47-61.

Grulke, E., Reed, K., Beck, M., Huang, X., Cormack, A. \& Seal, S., 2014. Nanoceria: factors affecting its pro- and anti- oxidant properties. Environ Sci: Nano, 1, 429444.

Grulke, E.A., Yokel, R.A., Hancock, M.L., Wellman, T. \& Beck, M., 2018, submitted. Surface-controlled model for nanoceria dissolution in carboxylic acid solution. Langmuir.

He, X., Zhang, H., Ma, Y., Bai, W., Zhang, Z., Lu, K., Ding, Y., Zhao, Y. \& Chai, Z., 2010. Lung deposition and extrapulmonary translocation of nano-ceria after intratracheal instillation Nanotechnology, 21, 285103/1-285103/8.

Heckman, K.L., Decoteau, W., Estevez, A., Reed, K.J., Costanzo, W., Sanford, D., Leiter, J.C., Clauss, J., Knapp, K., Gomez, C., Mullen, P., Rathbun, E., Prime, K., Marini, J., Patchefsky, J., Patchefsky, A.S., Hailstone, R.K. \& Erlichman, J.S., 2013. Custom cerium oxide nanoparticles protect against a free radical mediated autoimmune degenerative disease in the brain. ACS Nano, 7, 1058210596.

Heller, A., Barkleit, A., Foerstendorf, H., Tsushima, S., Heim, K. \& Bernhard, G., 2012. Curium(III) citrate speciation in biological systems: a europium(III) assisted spectroscopic and quantum chemical study. Dalton Tran., 41, 13969-13983.

Hoskins, C., Cuschieri, A. \& Wang, L., 2012. The cytotoxicity of polycationic iron oxide nanoparticles: common endpoint assays and alternative approaches for improved understanding of cellular response mechanism. J Nanobiotechnol, 10, 15.

Kagan, V.E., Konduru, N.V., Feng, W., Allen, B.L., Conroy, J., Volkov, Y., Vlasova, I.I., Belikova, N.A., Yanamala, N., Kapralov, A., Tyurina, Y.Y., Shi, J., Kisin, E.R., Murray, A.R., Franks, J., Stolz, D., Gou, P., Klein-Seetharaman, J., Fadeel, B., Star, A. \& Shvedova, A.A., 2010. Carbon nanotubes degraded by neutrophil 
myeloperoxidase induce less pulmonary inflammation. Nature Nanotechnol, 5, 354-359.

Keller, J., Wohlleben, W., Ma-Hock, L., Strauss, V., Gröters, S., Küttler, K., Wiench, K., Herden, C., Oberdörster, G., Van Ravenzwaay, B. \& Landsiedel, R., 2014. Time course of lung retention and toxicity of inhaled particles: short-term exposure to nano-Ceria. Archives Toxicol, 88, 2033-2059.

Kim, C.K., Kim, T., Choi, I.-Y., Soh, M., Kim, D., Kim, Y.-J., Jang, H., Yang, H.-S., Kim, J.Y., Park, H.-K., Park, S.P., Park, S., Yu, T., Yoon, B.-W., Lee, S.-H. \& Hyeon, T., 2012. Ceria nanoparticles that can protect against ischemic stroke. Angewandte Chem Int Ed, 51, 11039-11043.

Kitsou, I., Roussi, E. \& Tsetsekou, A., 2017. Synthesis of aqueous nanodispersed nanocrysralline ceria suspensions by a novel organic/inorganic precipitation method. Ceramics Int, 43, 3861-3865.

Kurian, M. \& Kunjachan, C., 2014. Investigation of size dependency on lattice strain of nanoceria particles synthesised by wet chemical methods. Int Nano Lett, 4, 7380.

Laux, P., Riebeling, C., Booth, A.M., Brain, J.D., Brunner, J., Cerrillo, C., Creutzenberg, O., Estrela-Lopis, I., Gebel, T., Johanson, G., Jungnickel, H., Kock, H., Tentschert, J., Tlili, A., Schäffer, A., Sips, A.J.a.M., Yokel, R.A. \& Luch, A., 2017. Biokinetics of nanomaterials: The role of biopersistence. NanoImpact, 6, 69-80.

Leal, R.S., 1959. Composition and stability constant of a complex of cerium and ammonium citrate at alkaline pH. J Inorg Nucl Chem, 10, 159-61.

Legiša, M. \& Kidrič, J., 1989. Initiation of citric acid accumulation in the early stages of Aspergillus niger growth. Appl Microbiol Biotechnol, 31, 453-7.

Li, H., Yang, Z.-Y., Liu, C., Zeng, Y.-P., Hao, Y.-H., Gu, Y., Wang, W.-D. \& Li, R., 2015. PEGylated ceria nanoparticles used for radioprotection on human liver cells under $\gamma$-ray irradiation. Free Radical Biol Med, 87, 26-35.

Madero-Visbal, R.A., Alvarado, B.E., Colon, J.F., Baker, C.H., Wason, M.S., Isley, B., Seal, S., Lee, C.M., Das, S. \& Manon, R., 2012. Harnessing nanoparticles to improve toxicity after head and neck radiation. Nanomedicine (New York, NY, U. S.), 8, 1223-1231.

Marchioni, M., Gallon, T., Worms, I., Jouneau, P.-H., Lebrun, C., Veronesi, G., Truffier-Boutry, D., Mintz, E., Delangle, P., Deniaud, A. \& Michaud-Soret, I., 2018. Insights into polythiol-assisted AgNP dissolution induced by bio-relevant molecules. Environ Sci: Nano, Ahead of Print.

Masui, T., Hirai, H., Imanaka, N., Adachi, G., Sakata, T. \& Mori, H., 2002. Synthesis of cerium oxide nanoparticles by hydrothermal crystallization with citric acid. $J$ Mat Sci Letters, 21, 489-491.

Molina, R.M., Konduru, N.V., Jimenez, R.J., Pyrgiotakis, G., Demokritou, P., Wohlleben, W. \& Brain, J.D., 2014. Bioavailability, distribution and clearance of tracheally instilled, gavaged or injected cerium dioxide nanoparticles and ionic cerium. Environ Sci: Nano, 1, 561-573.

Pesic, M., Podolski-Renic, A., Stojkovic, S., Matovic, B., Zmejkoski, D., Kojic, V., Bogdanovic, G., Pavicevic, A., Mojovic, M., Savic, A., Milenkovic, I., Kalauzi, A. \& Radotic, K., 2015. Anti-cancer effects of cerium oxide nanoparticles and its intracellular redox activity. Chem-Biol Interact, 232, 85-93.

Plakhova, T.V., Romanchuk, A.Y., Yakunin, S.N., Dumas, T., Demir, S., Wang, S., Minasian, S.G., Shuh, D.K., Tyliszczak, T., Shiryaev, A.A., Egorov, A.V., Ivanov, V.K. \& Kalmykov, S.N., 2016. Solubility of nanocrystalline cerium 
dioxide: experimental data and thermodynamic modeling. J Phys Chem C, 120, 22615-22626.

Reed, K., Cormack, A., Kulkarni, A., Mayton, M., Sayle, D., Klaessig, F. \& Stadler, B., 2014. Exploring the properties and applications of nanoceria: is there still plenty of room at the bottom? Environ Sci: Nano, 1, 390-405.

Rui, Y., Zhang, P., Zhang, Y., Ma, Y., He, X., Gui, X., Li, Y., Zhang, J., Zheng, L., Chu, S., Guo, Z., Chai, Z., Zhao, Y. \& Zhang, Z., 2015. Transformation of ceria nanoparticles in cucumber plants is influenced by phosphate. Environ Pollution, 198, 8-14.

Selvaraj, V., Manne, N.D.P.K., Arvapalli, R., Rice, K.M., Nandyala, G., Fankenhanel, E. \& Blough, E.R., 2015. Effect of cerium oxide nanoparticles on sepsis induced mortality and NF- $\mathrm{BB}$ signaling in cultured macrophages. Nanomedicine (London, U. K.), 10, 1275-1288.

Senanayake, S.D., Stacchiola, D. \& Rodriguez, J.A., 2013. Unique properties of ceria nanoparticles supported on metals: Novel inverse ceria/copper catalysts for CO oxidation and the water-gas shift reaction. Acc Chem Res, 46, 1702-1711.

Siriwardane, I.W., 2012. Adsorption of citric acid on cerium oxide nanoparticles (nanoceria): effects of $\mathrm{pH}$, surface charge and aggregation. University of Iowa, http://ir.uiowa.edu/etd/3385.

Soenen, S.J.H., Himmelreich, U., Nuytten, N., Pisanic Ii, T.R., Ferrari, A. \& De Cuyper, M., 2010. Intracellular nanoparticle coating stability determines nanoparticle diagnostics efficacy and cell functionality. Small, 6, 2136-2145.

Taguchi, M., Takami, S., Naka, T. \& Adschiri, T., 2009. Growth mechanism and surface chemical characteristics of dicarboxylic acid-modified $\mathrm{CeO}_{2}$ nanocrystals produced in supercritical water: tailor-made water-soluble $\mathrm{CeO}_{2}$ nanocrystals. Crystal Growth Design, 9, 5297-5303.

Vlasova, I.I., Kapralov, A.A., Michael, Z.P., Burkert, S.C., Shurin, M.R., Star, A., Shvedova, A.A. \& Kagan, V.E., 2016. Enzymatic oxidative biodegradation of nanoparticles: Mechanisms, significance and applications. Toxicol Appl Pharmacol, 299, 58-69.

Wohlleben, W., Ma-Hock, L., Boyko, V., Cox, G., Egenolf, H., Freiberger, H., Hinrichsen, B., Hirth, S. \& Landsiedel, R., 2013. Nanospecific guidance in REACH: A comparative physical-chemical characterization of 15 materials with methodical correlations J Ceramic Sci Technol, 4, 93-104.

Wong, L.L., Hirst, S.M., Pye, Q.N., Reilly, C.M., Seal, S. \& Mcginnis, J.F., 2013. Catalytic nanoceria are preferentially retained in the rat retina and are not cytotoxic after intravitreal injection. PLOS ONE, 8, e58431.

Wong, L.L. \& Mcginnis, J.F., 2014. Nanoceria as bona fide catalytic antioxidants in medicine: what we know and what we want to know ... Adv Exp Med Biol, 801, 821-8.

Yokel, R.A., Au, T.C., Macphail, R., Hardas, S.S., Butterfield, D.A., Sultana, R., Goodman, M., Tseng, M.T., Dan, M., Haghnazar, H., Unrine, J.M., Graham, U.M., Wu, P. \& Grulke, E.A., 2012. Distribution, elimination, and biopersistence to 90 days of a systemically introduced $30 \mathrm{~nm}$ ceria-engineered nanomaterial in rats. Toxicol Sci, 127, 256-268.

Yokel, R.A., Florence, R.L., Unrine, J.M., Tseng, M.T., Graham, U.M., Wu, P., Grulke, E.A., Sultana, R., Hardas, S.S. \& Butterfield, D.A., 2009. Biodistribution and oxidative stress effects of a systemically-introduced commercial ceria engineered nanomaterial. Nanotoxicology, 3, 234-248. 
Zabrieski, Z., Morrell, E., Hortin, J., Dimkpa, C., Mclean, J., Britt, D. \& Anderson, A., 2015. Pesticidal activity of metal oxide nanoparticles on plant pathogenic isolates of Pythium. Ecotoxicol, 24, 1305-1314.

Zhang, Y., Lin, Y., Jing, C. \& Qin, Y., 2007. Formation and thermal decomposition of cerium-organic precursor for nanocrystalline cerium oxide powder synthesis. $J f$ Dispersion Sci Technoy, 28, 1053-1058.

Zhou, R.-S., Song, J.-F., Yang, Q.-F., Xu, X.-Y., Xu, J.-Q. \& Wang, T.-G., 2008.

Syntheses, structures and magnetic properties of a series of $2 \mathrm{D}$ and $3 \mathrm{D}$

lanthanide complexes constructed by citric ligand. J Mol Struct, 877, 115-122. 
Table 1. Bath solution additives

\begin{tabular}{|l|l|l|}
\hline Bath solution additive & $\mathbf{p H}$ & Concentration(s) \\
\hline Water & $\sim 6$ & \\
\hline $\mathrm{HRP}+\mathrm{H}_{2} \mathrm{O}_{2}$ & 6.1 & $0.67 \mathrm{mg} \mathrm{HRP}, 40 \mu \mathrm{M} \mathrm{H}_{2} \mathrm{O}_{2}$ \\
\hline Ammonium & 4.5 & $20 \mathrm{mM}$ \\
\hline Carboxylic acids & & \\
\hline Acetic acid & 4.5 & $20 \mathrm{mM}$ \\
\hline Adipic acid & 4.5 & $110 \mathrm{mM}$ \\
\hline Citric acid & 4.5 & $110 \mathrm{mM}$ \\
\hline Glutaric acid & 4.5 & $110 \mathrm{mM}$ \\
\hline DL-3-hydroxybutyric acid & 4.5 & $110 \mathrm{mM}$ \\
\hline Lactic acid & 4.5 & $110 \mathrm{mM}$ \\
\hline DL-Malic & 4.5 & $110 \mathrm{mM}$ \\
\hline Pimelic acid & 4.5 & $110 \mathrm{mM}$ \\
\hline Succinic acid & 4.5 & $110 \mathrm{mM}$ \\
\hline Tricarballylic acid & 4.5 & $110 \mathrm{mM}$ \\
\hline
\end{tabular}


Table 2. Sampling protocol for cerium mass and nanoceria size

\begin{tabular}{|c|c|c|c|c|c|}
\hline CHAMBER & $\begin{array}{c}\text { SAMPLE } \\
\text { TYPE }\end{array}$ & TIME & VOLUME & PURPOSE & ANALYSIS \\
\hline \multirow{5}{*}{ Cassette } & \multirow{5}{*}{$\begin{array}{l}\text { Nanoceria } \\
\text { dispersion }\end{array}$} & $\mathrm{t}<0$ & $75 \mu \mathrm{l}$ & Ce concentration & ICP-MS \\
\hline & & $\begin{array}{l}8,16, \& \\
24 \text { weeks }\end{array}$ & $\begin{array}{l}75 \mu l \text { each } \\
\text { time }\end{array}$ & Ce concentration & ICP-MS \\
\hline & & & $\begin{array}{l}\sim 10 \text { or } 25 \mu l \\
\text { each time }\end{array}$ & Nanoceria size & TEM/STEM \\
\hline & & \multirow[t]{2}{*}{ Final } & $75 \mu l$ & Ce concentration & ICP-MS \\
\hline & & & $10 \mu \mathrm{l}$ & Nanoceria size & TEM/STEM \\
\hline \multirow{5}{*}{ Bath } & \multirow{5}{*}{$\begin{array}{l}\text { Bath } \\
\text { solution }\end{array}$} & $\mathrm{t}<0$ & $1 \mathrm{ml}$ & Ce concentration & ICP-MS \\
\hline & & weekly & $1 \mathrm{ml}$ each time & Ce concentration & ICP-MS \\
\hline & & $\begin{array}{l}4,8,16, \& \\
24 \text { weeks }\end{array}$ & $\begin{array}{l}\sim 5 \mu l \text { each } \\
\text { time }\end{array}$ & Nanoceria size & TEM/STEM \\
\hline & & \multirow[t]{2}{*}{ Final } & $1 \mathrm{ml}$ & Ce concentration & ICP-MS \\
\hline & & & $\sim 5 \mu \mathrm{l}$ & Nanoceria size & TEM/STEM \\
\hline
\end{tabular}


Table 3. Model estimates of dissolution half-life (h) and average nanoceria diameter at 28 weeks from the replicate experiments.

\begin{tabular}{|l|l|l|}
\hline \multicolumn{1}{|c|}{ Bath solution } & Dissolution half-life (h) & $\begin{array}{l}\text { Average diameter at } \\
\mathbf{2 8} \text { weeks (nm) }\end{array}$ \\
\hline $\mathbf{p H ~} \sim \mathbf{6}$ & & \\
\hline Water & 58,200 & 4.17 \\
\hline HRP & $55,200,105,000$ & $4.16,4.19$ \\
\hline pH 4.5 & & \\
\hline Ammonium & 7490 & 3.69 \\
\hline Glutaric acid & 3030,3300 & $2.88,2.99$ \\
\hline Tricarballylic acid & 2310,4400 & $2.46,3.30$ \\
\hline DL-3-hydroxybutyric acid & 2310,3300 & $2.46,2.99$ \\
\hline Pimelic acid & 2310,2620 & $2.46,2.96$ \\
\hline Acetic acid & 2290,2300 & $2.45,2.83$ \\
\hline Citric acid & 1950,2270 & $2.13,2.42$ \\
\hline Adipic acid & 1990,2310 & $2.18,2.46$ \\
\hline Succinic acid & 1560,2080 & $1.78,2.47$ \\
\hline DL-Malic acid & 1420,1960 & $1.70,2.23$ \\
\hline Lactic acid & 794,811 & Dissolved at 18 weeks \\
\hline
\end{tabular}


Figure 1. Structures of the carboxylic acids of the present study.

Figure 2. Cartoon of the bath-cassette system, evaporative losses, and sampling protocol.

Figure 3. Hydrodynamic diameter and TEM/STEM analysis of nanoceria. (a) Hydrodynamic diameter as surface area. (b) Hi-res TEM/STEM image of individual (primary) $\sim 4 \mathrm{~nm}$ particles and their secondary structure (agglomerate). (c) Nanoceria primary particle polycrystalline nature (dominant faces $\{100\}$ and $\{111\})$. (d) Representative nanoceria particles, of 20 measured, showing d-spacings that ranged from 3.15 to $3.17 \AA$ and lattice unit cells ranging from 5.40 to $5.41 \AA$.

Figure 4. Percentage of nanoceria dissolved vs. time for 12 bath solution additives (Table 1).

Figure 5. Nanoparticle size over time. Effective nanoceria agglomerate hydrodynamic diameter over time during exposure to $0.11,1.1,11$ or $110 \mathrm{mM}$ citric (left panel) or malic acid (right panel).

Figure 6. Partially degraded nanoceria, evidenced by rounding at the edges and smaller primary particle size after $1344 \mathrm{~h}$ exposure to citric acid at $\mathrm{pH} 4.5$. 
Figure 7. HRTEM images of nanoceria withdrawn from cassettes. Primary, secondary, and tertiary structures of nanoceria-ligand complexes are shown for each ligand. A representative image of nanoceria in the presence of each ligand at three different time intervals is shown (Phase 1 at 4 weeks; Phase 2 at 12 weeks; and Phase 3 at 28 weeks). Details follow.

- a,b,c: HRP $+\mathrm{H}_{2} \mathrm{O}_{2}$. Nanoceria secondary agglomerates heavily associated to form aligned and dense tertiary superstructures in Phase 1; no reduction in primary or secondary particle size or rounding of nanoceria crystals in Phase 2 or Phase 3 and residual superstructures in Phase 3.

- d,e,f: ammonium. Several hundred nm wide tertiary superstructures formed in Phase 1, no recognizable size reduction due to dissolution of nanoceria in Phase 2 and similar superstructures and particle sizes in Phase 3.

- g,h,i: glutaric acid. Superstructures with unique long-range string of pearl arrangements in Phase 1; rounding of nanoceria in the secondary agglomerates in Phase 2; skeletal agglomerates in Phase 3.

- $\mathrm{j}, \mathrm{k}, \mathrm{l}$ : tricarballylic acid. Uniquely arranged superstructures with long-range in Phase 1; rounding of nanoceria in the secondary agglomerates in Phase 2; skeletal agglomerates in Phase 3.

- m,n,o: hydroxybutyric acid. Short-range superstructures (only involving a select few aligned agglomerates) in Phase 1; rounding of nanoceria in the secondary agglomerates in Phase 2; skeletal secondary agglomerates in Phase 3 with some isolated nanoceria.

- p,q,r: pimelic acid. Short range superstructures in Phase 1; rounding of nanoceria in Phase 2 with some skeletal agglomerates; more skeletal agglomerates in Phase 3 with isolated nanoceria also more common. 
- $\quad \mathrm{s}, \mathrm{t}, \mathrm{u}$ : acetic acid. Short range superstructures in Phase 1; rounding of nanoceria in Phase 2 with breakup of skeletal agglomerates and release of isolated nanoceria; Phase 3 skeletal agglomerates with very small and rounded nanoceria.

- $\quad \mathrm{v}, \mathrm{w}, \mathrm{x}$ : citric acid. Minor formation of tertiary superstructure in Phase 1; rounding of nanoceria crystals in Phase 2; breakup of superstructures in Phase 3 and skeletal appearance of secondary agglomerates.

- y,z,aa: adipic acid. Very few superstructures in Phase 1; extensive rounding of nanoceria in agglomerates in Phase 2; no superstructures in Phase 3 and greatly reduced amount of secondary agglomerates with major skeletal development and more isolated nanoceria.

- ab,ac,ad: succinic acid. Isolated superstructures in Phase 1 with most secondary agglomerates not attached to other agglomerates; major skeletal development in agglomerates in Phase 2; secondary agglomerates are much smaller compared with the starting materials shown in Figure 3 and isolated nanoceria are also reduced in size.

- ae,af,ag: malic acid. No superstructures and some rounding of nanoceria in agglomerates in Phase 1; strong rounding of nanoceria in Phase 2 with skeletal appearance of agglomerates; isolated small-sized agglomerates (some only harboring a few nanoceria) and overall quantities of nanoceria greatly reduced compared with Phase 1.

- ah,ai,aj: lactic acid. No superstructures and only individual secondary agglomerates in Phase 1; Phase 2 has reduced nanoceria size and skeletal appearance of the agglomerates; Phase 3 shows only very few isolated very 
small agglomerates or individual nanoceria at greatly reduced size and quantities compared with Phase 1.

Figure 8. EM images and EELS analysis for nanoceria as synthesized and after exposure to citric acid at $\mathrm{pH} 4.5$ at Phase 1 (a) and Phase 2 (b). M4/M5 peaks for cerium are indicated. 
Figure 1.

Acetic acid<smiles>CC(=O)O</smiles>

Lactic acid<smiles>CC(O)C(=O)O</smiles>

Malic acid<smiles>O=C(O)CC(O)C(=O)O</smiles>

Citric acid<smiles>O=C(O)CC(O)(CC(=O)O)C(=O)O</smiles>

Tricarballylic acid

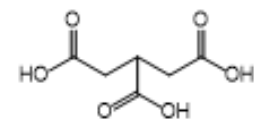

Hydroxybutyric acid<smiles>CC(O)CC(=O)O</smiles>

Succinic acid<smiles>O=C(O)CCC(=O)O</smiles>

Glutaric acid<smiles>O=C(O)CCCC(=O)O</smiles>

Adipic acid<smiles>O=C(O)CCCCC(=O)O</smiles>

Pimelic acid<smiles>O=C(O)CCCCCC(=O)O</smiles> 
Figure 2.

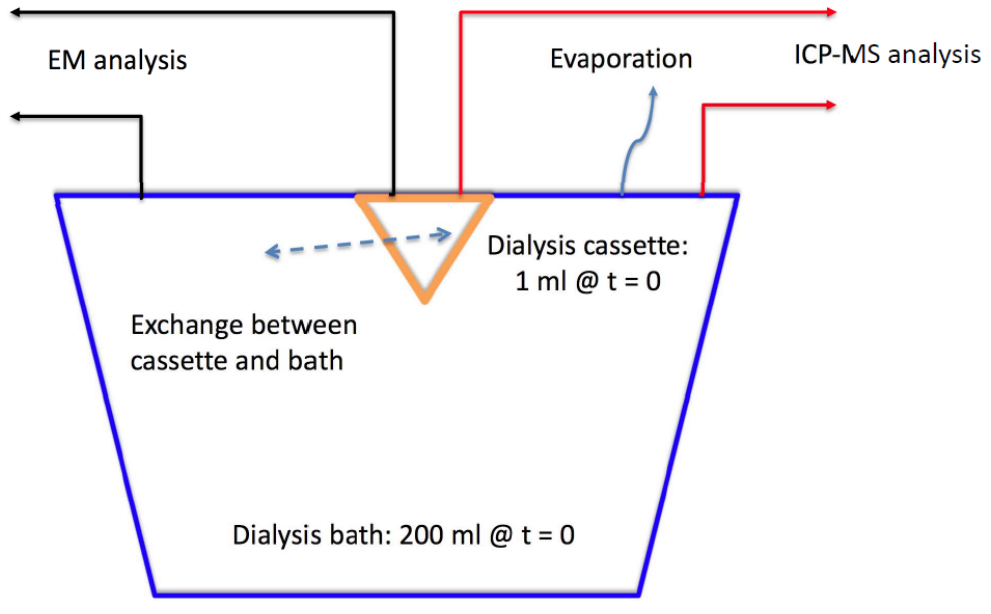


Figure 3.
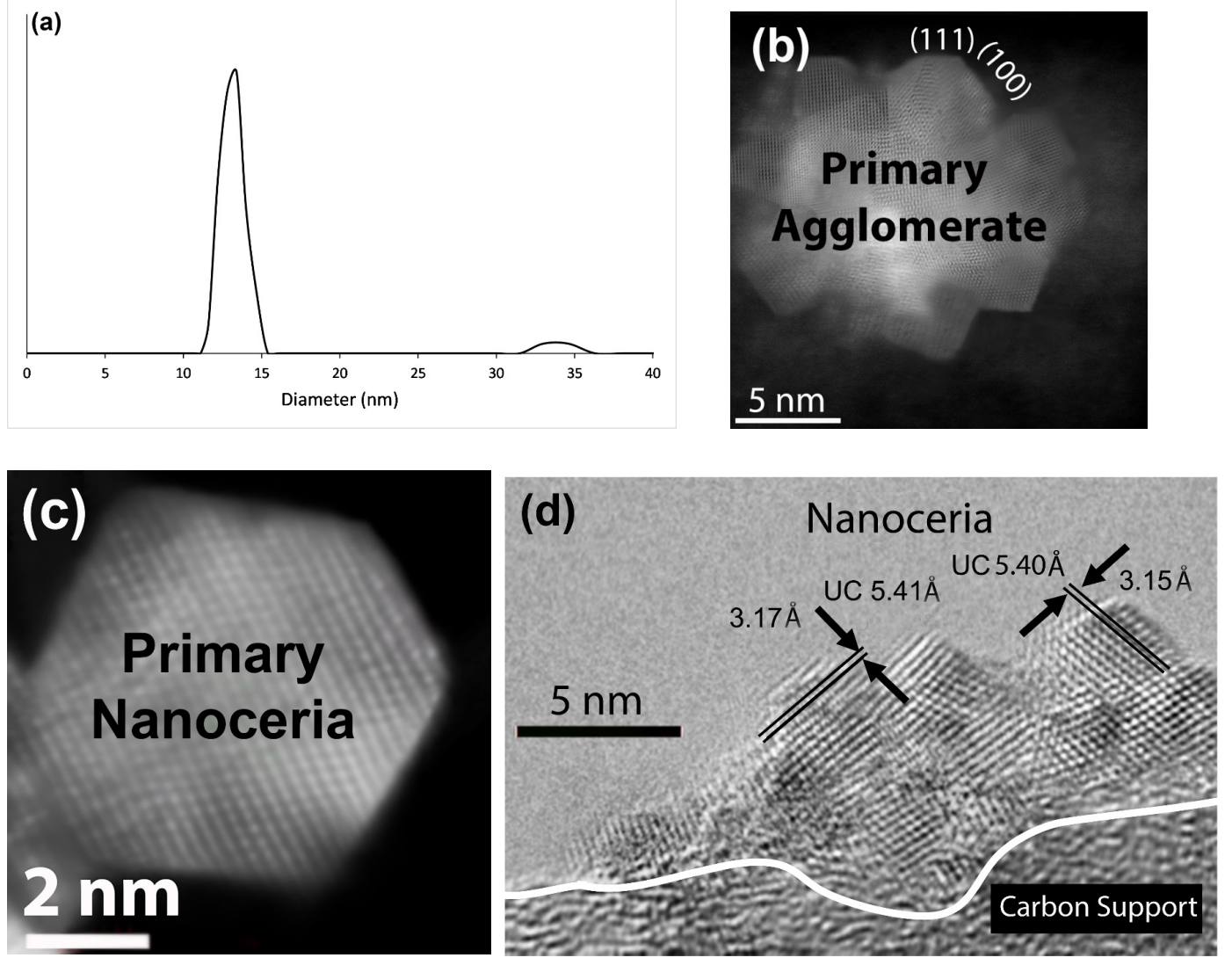
Figure 4.
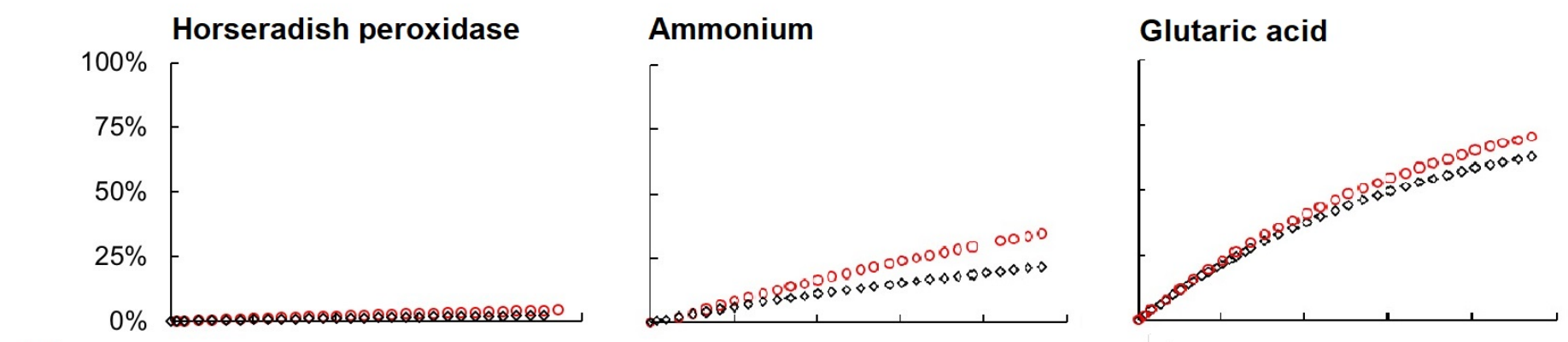



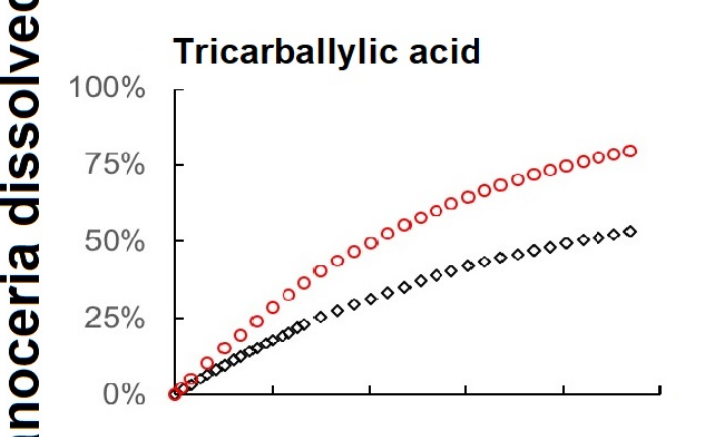

\section{Hydroxybutyric acid}

Pimelic acid
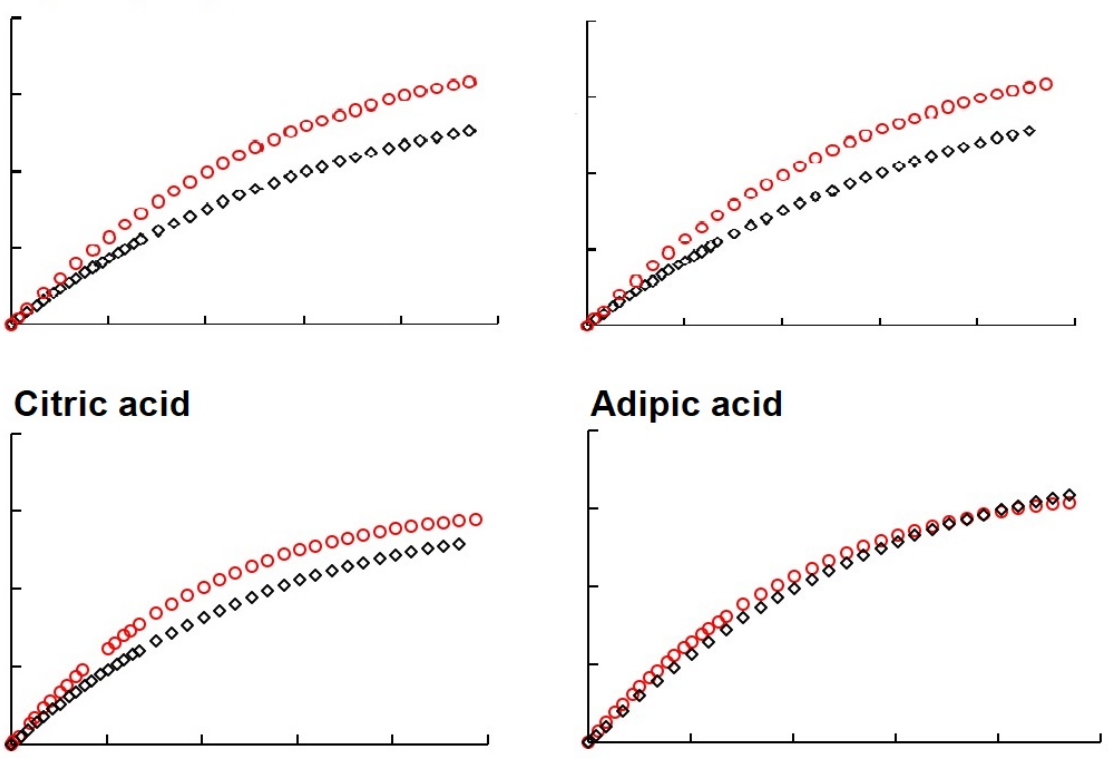

Malic acid

\section{Lactic acid}
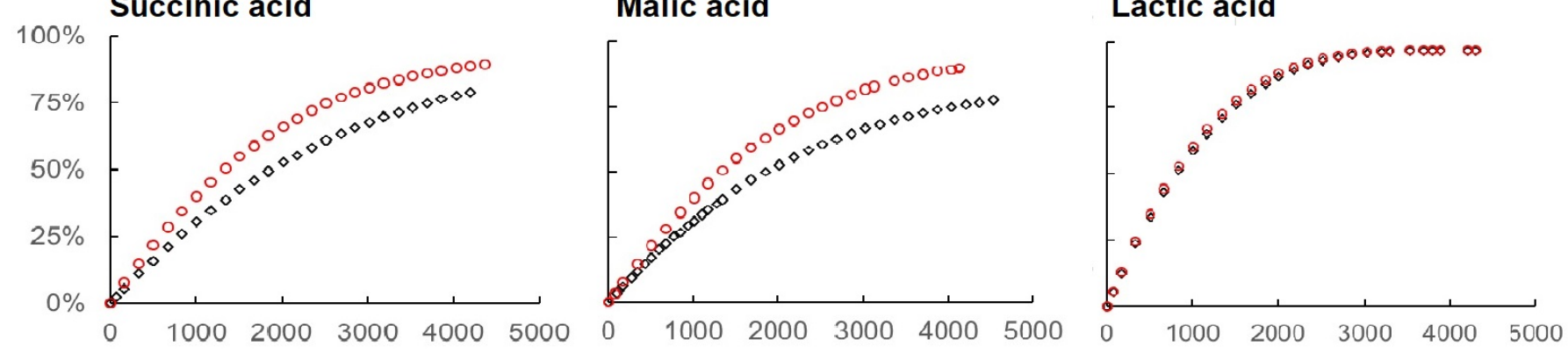

Time (h) 
Figure 5.
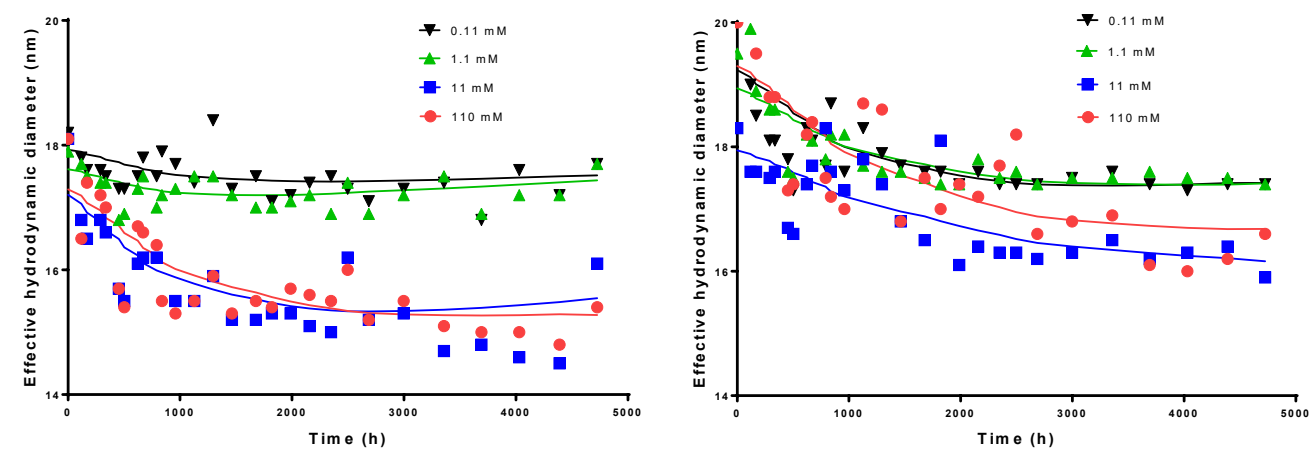
Figure 6.

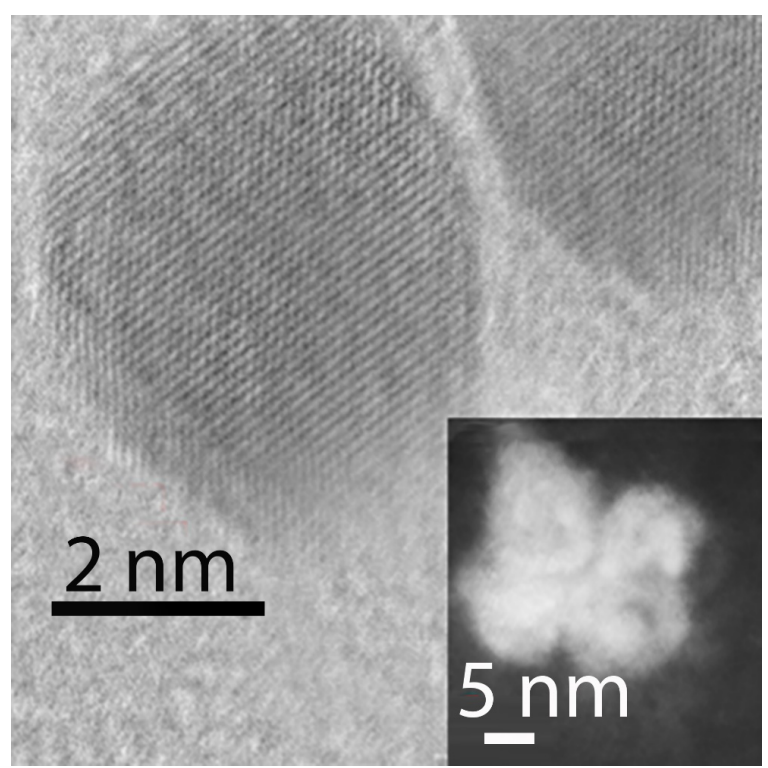


Figure 7.
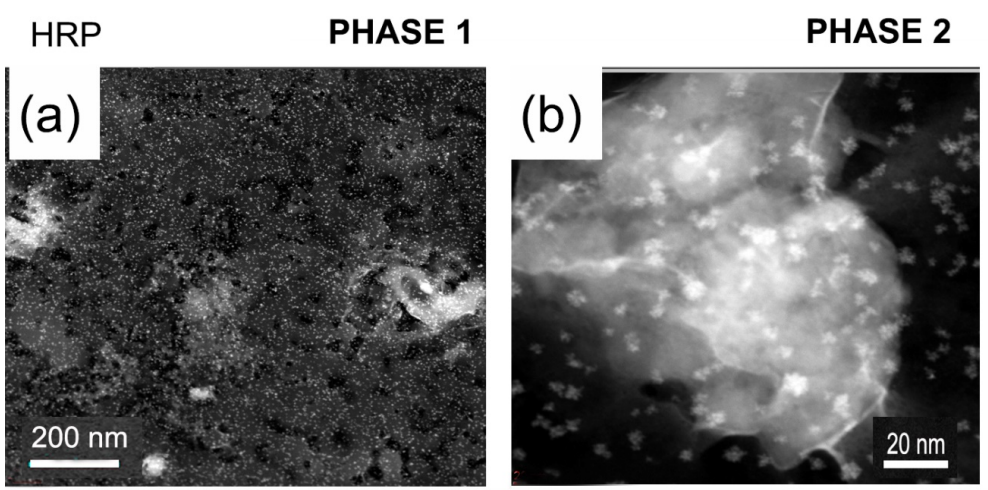

PHASE 3
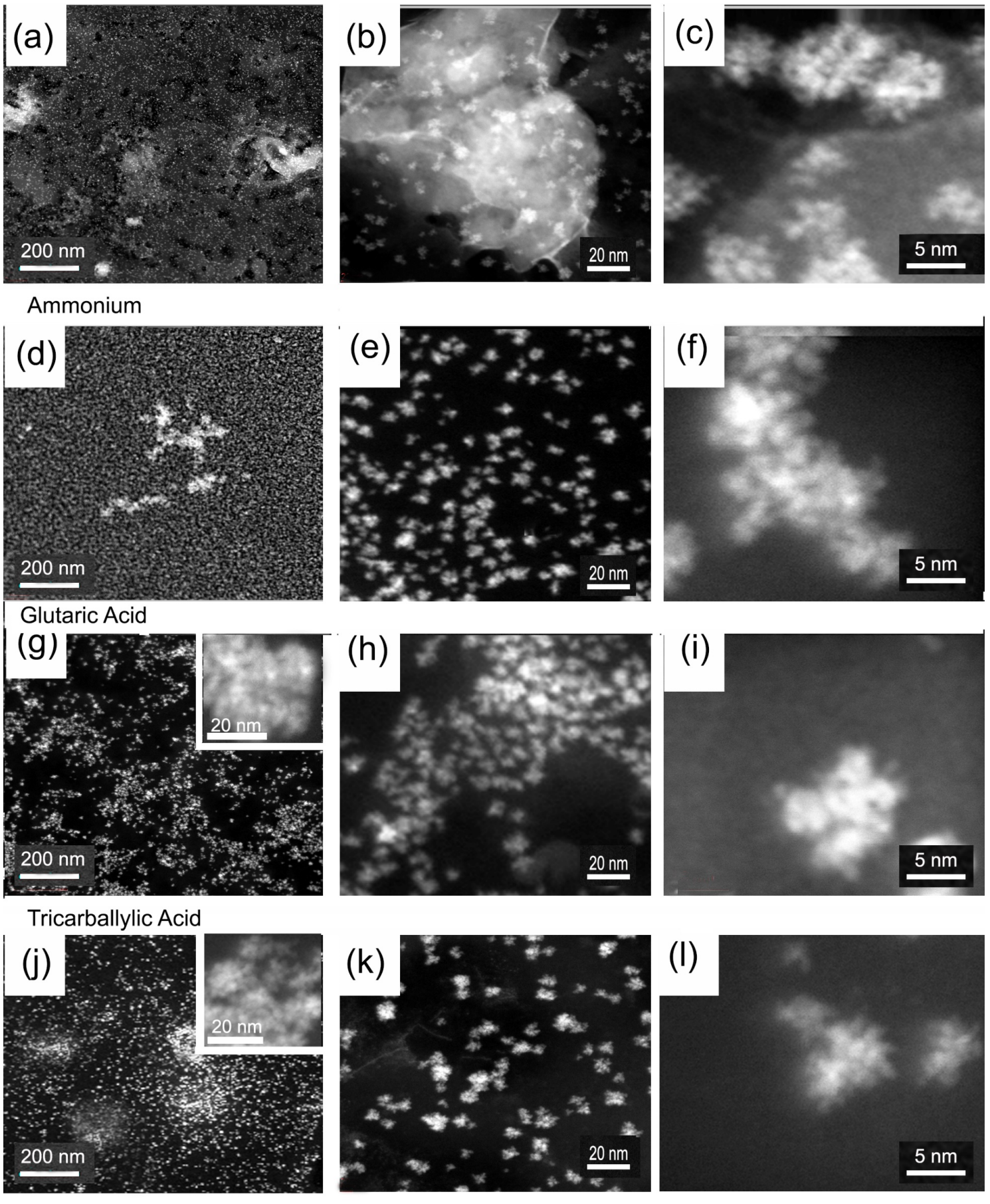

(i)
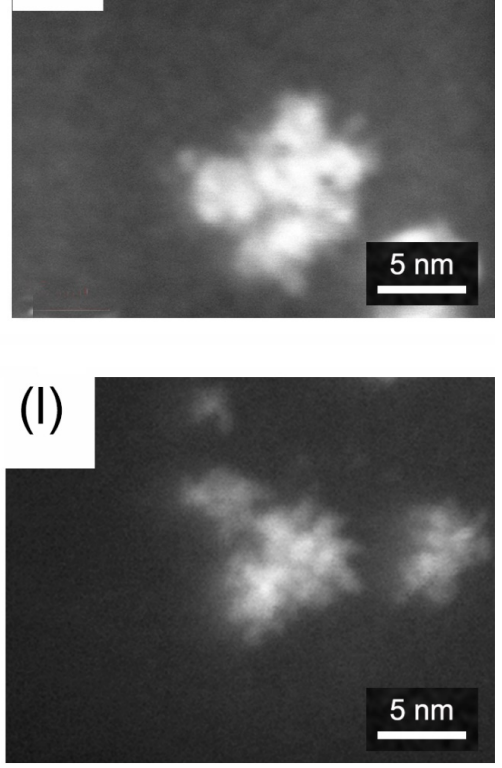


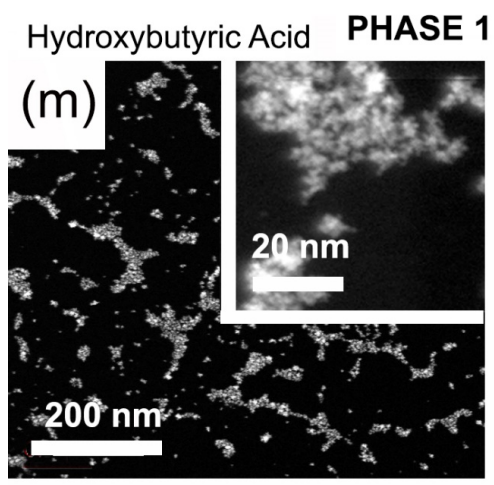

PHASE 2

PHASE 3

Pimelic Acid
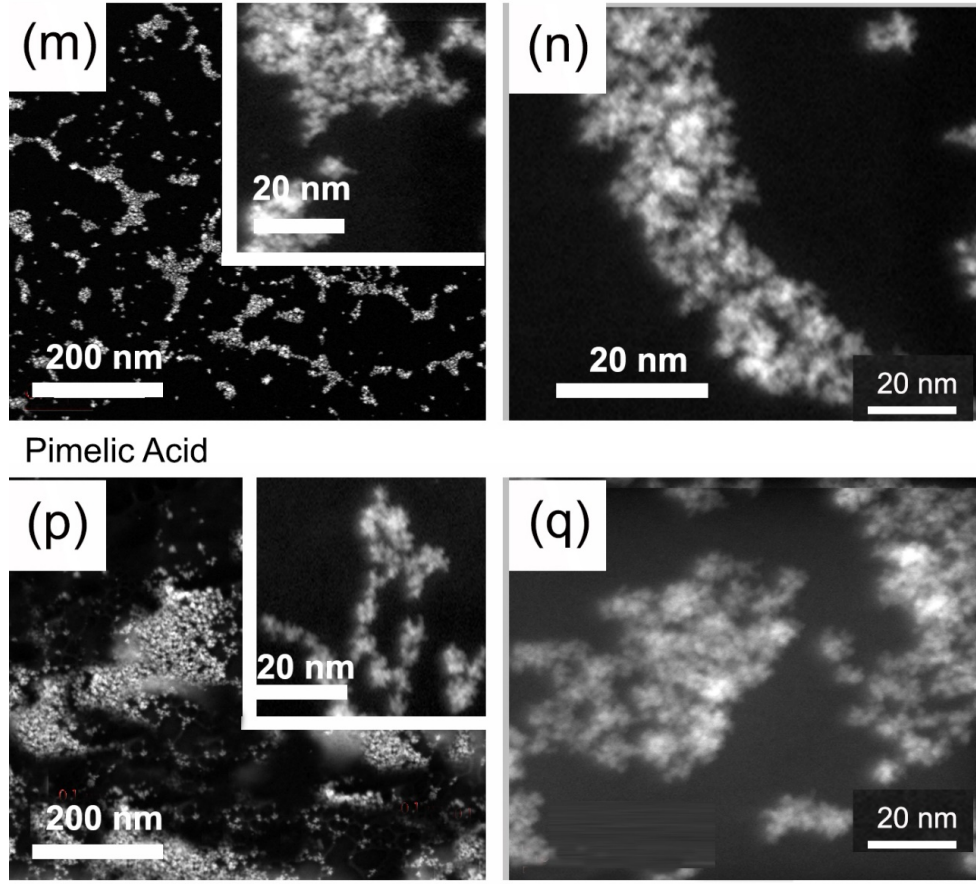

(o)

$5 \mathrm{~nm}$
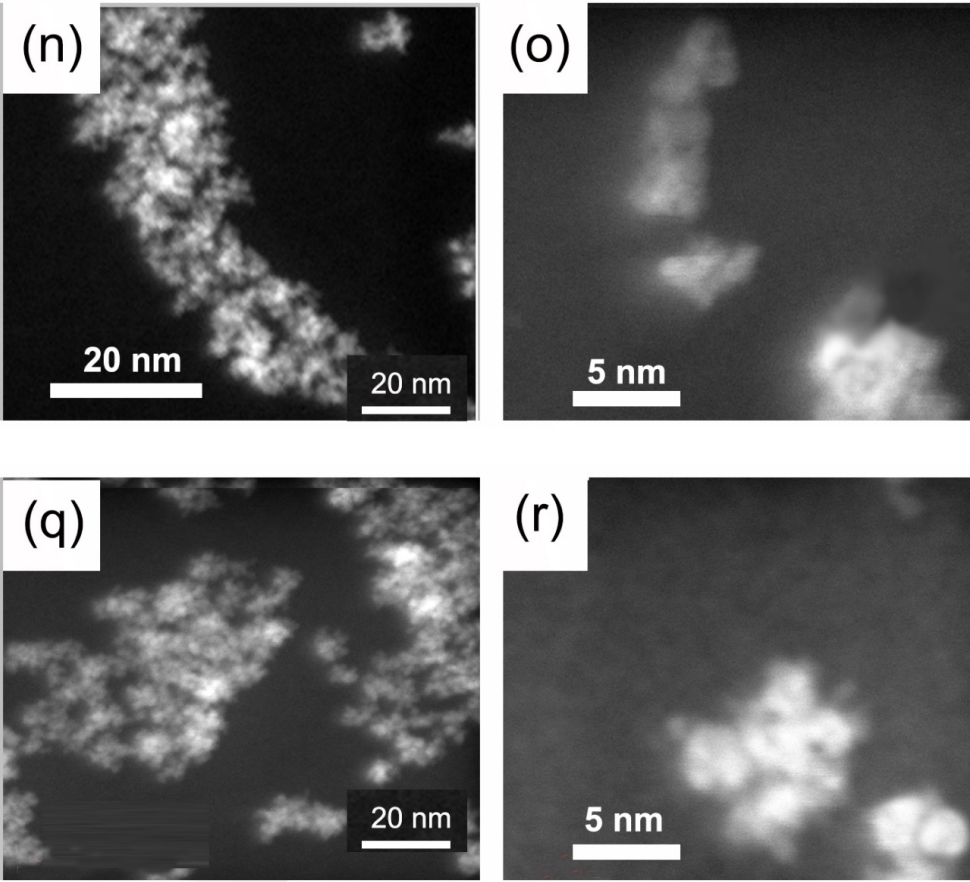

(r)
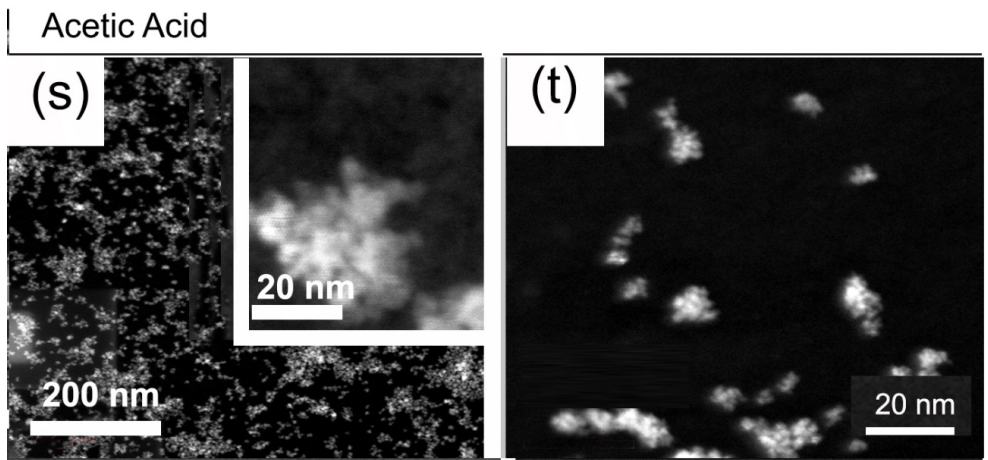

(u)

$5 \mathrm{~nm}$

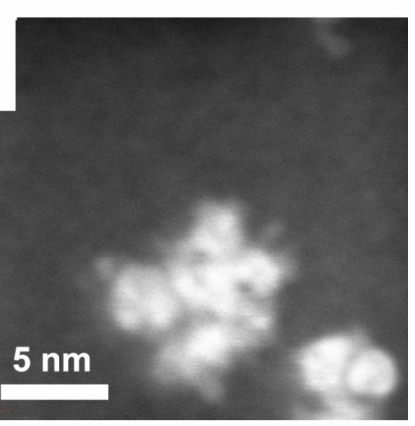

Citric Acid
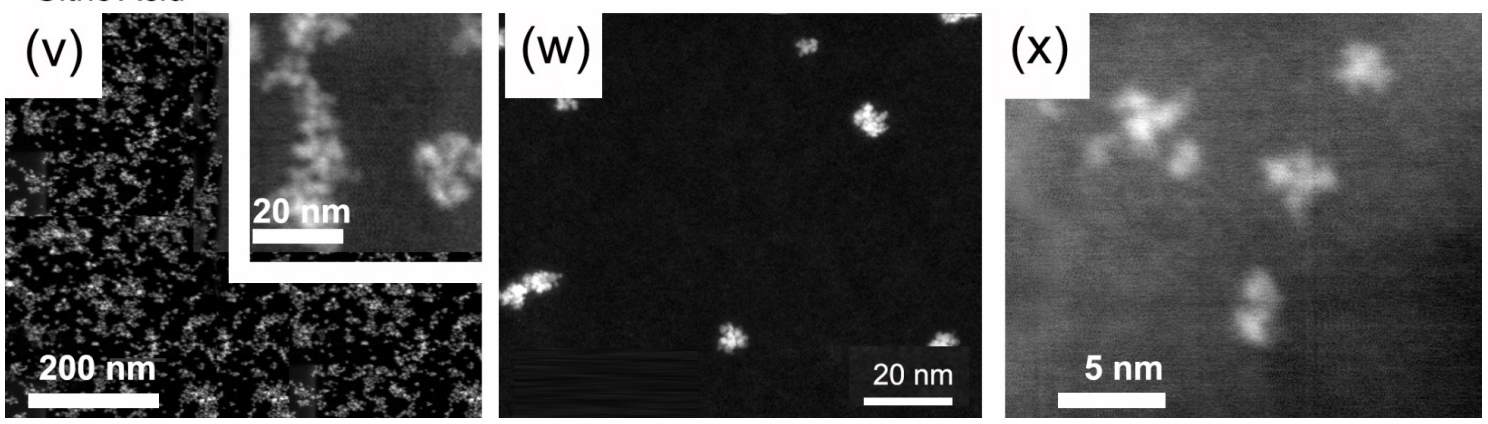


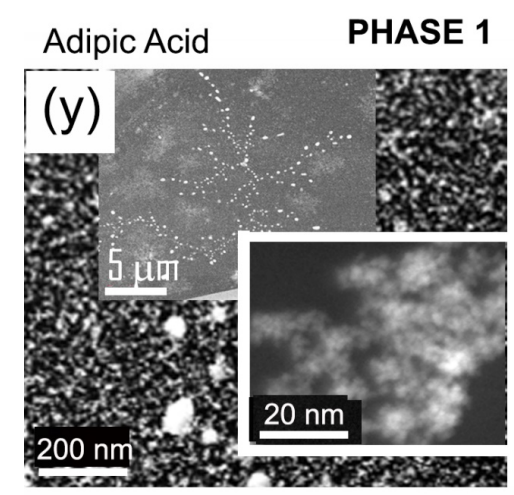

PHASE 2

PHASE 3
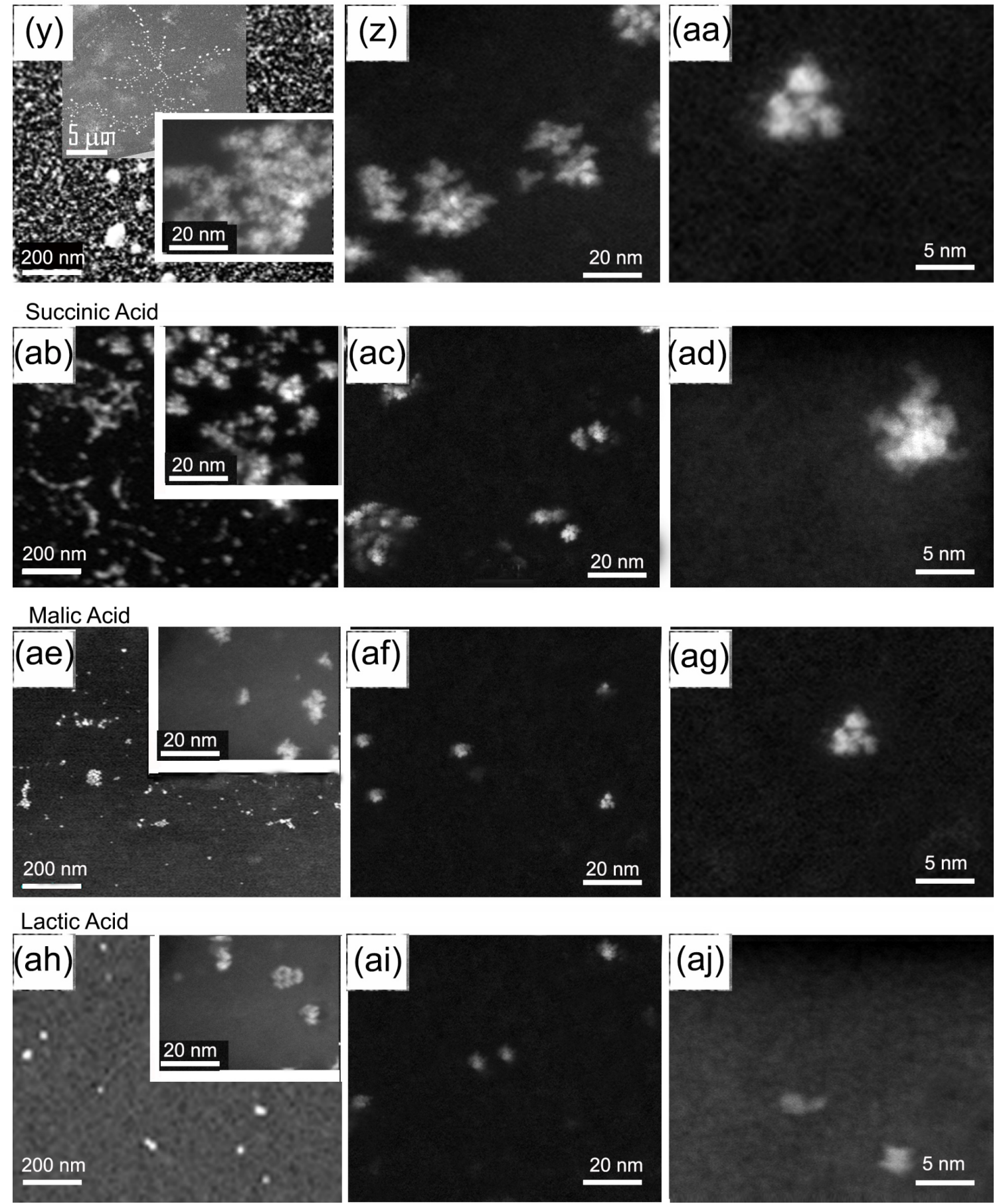
Figure 8.
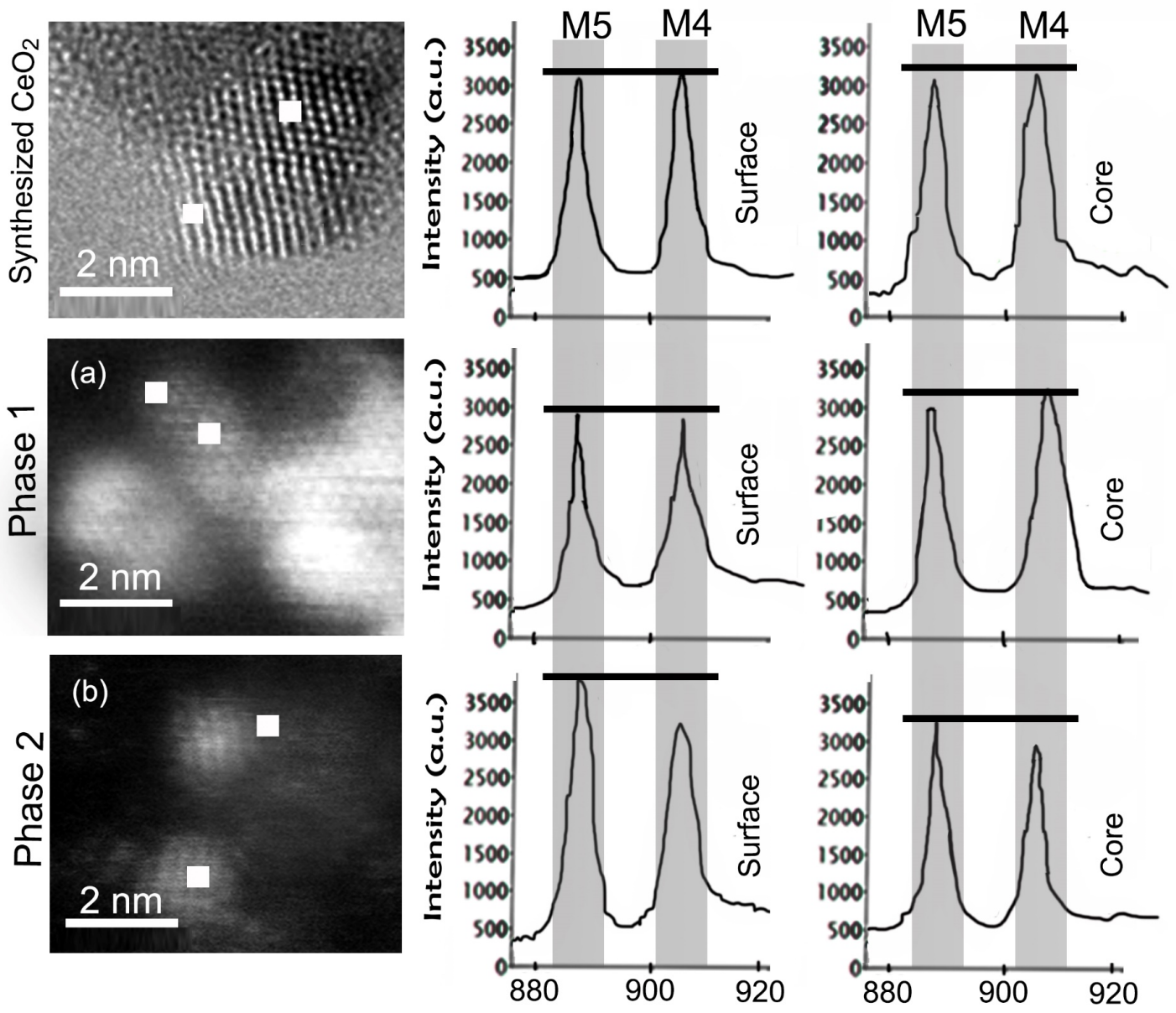

Energy Loss (eV) 


\section{Supplemental Material: Carboxylic Acids Accelerate Acidic Environment- Mediated Nanoceria Dissolution}

\section{Cerium carboxylic acid stability constants}

Table S1. Cerium carboxylic acid stability constants from The National Institute of Standards and Technology Critically Selected Stability Constants of Metal Complexes database

\begin{tabular}{|c|c|c|c|c|c|c|c|}
\hline & $\begin{array}{l}\text { Cerium } \\
\text { valence }\end{array}$ & $\begin{array}{l}\text { Log } K \\
\text { value }\end{array}$ & & Beta 1 & Beta 2 & Beta 3 & Beta 4 \\
\hline \multicolumn{7}{|l|}{ Acetic acid } & \\
\hline & $\mathrm{Ce}+++$ & $\mathrm{K} 1=5.207$ & $\mathrm{~B} 2=9.96$ & $B 3=14.236$ & & & \\
\hline & $\mathrm{Ce}+++$ & & $\mathrm{B} 2=2.57$ & $\mathrm{~B} 3=2.72$ & & & \\
\hline & $\mathrm{Ce}+++$ & $\mathrm{K} 1=3.04$ & $B 2=4.90$ & B3 $=6.51$ & & & \\
\hline & $\mathrm{Ce}+++$ & $\mathrm{K} 1=1.70$ & & & & & \\
\hline & $\mathrm{Ce}+++$ & $\mathrm{K} 1=2.58$ & $\mathrm{~B} 2=4.70$ & B3=6.15 & $\mathrm{B} 4=7.16$ & B5=7.66 & \\
\hline & $\mathrm{Ce}+++$ & & & B3=3.31 & & & \\
\hline & $\mathrm{Ce}+++$ & $\mathrm{K} 1=2.09$ & $B 2=3.53$ & & & & \\
\hline & $\mathrm{Ce}+++$ & $K 1=1.68$ & $B 2=2.69$ & $B 3=3.13$ & $B 4=3.18$ & & \\
\hline & $\mathrm{Ce}+++$ & $\mathrm{K} 1=1.68$ & $B 2=2.65$ & $K 3=0.58$ & & & \\
\hline & $\begin{array}{l}\text { Median } \\
\mathrm{Ce+++}\end{array}$ & $K 1=2.09$ & $B 2=3.53$ & B3=3.31 & & & \\
\hline & $\mathrm{Ce}++++$ & & & $\begin{array}{l}\mathrm{K}(\mathrm{CeOH}+\mathrm{HL} \\
)=-0.41\end{array}$ & $\begin{array}{l}\mathrm{K}(2 \mathrm{CeOH}+\mathrm{H} \\
\mathrm{L}= \\
\mathrm{CeOCeL}+\mathrm{H})= \\
1.43\end{array}$ & $\begin{array}{l}\mathrm{K}(3 \mathrm{CeOH} \\
+\mathrm{HL}= \\
\mathrm{Ce} 3 \mathrm{O} 3(\mathrm{H} \\
\mathrm{L})+3 \mathrm{H})=5 \\
21\end{array}$ & \\
\hline \multicolumn{8}{|l|}{ L-Lactic acid } \\
\hline & $\mathrm{Ce}+++$ & $\mathrm{K} 1=6.32$ & $B 2=11.99$ & & & & \\
\hline & $\mathrm{Ce}+++$ & $\mathrm{K} 1=3.74$ & & & & & \\
\hline & $\mathrm{Ce}+++$ & $\mathrm{K} 1=3.78$ & & & & & \\
\hline
\end{tabular}




\begin{tabular}{|c|c|c|c|c|c|c|c|}
\hline & $\mathrm{Ce}+++$ & & & $\begin{array}{l}\mathrm{K}(\mathrm{Ce}+\mathrm{HL}=\mathrm{C} \\
\mathrm{eL}+\mathrm{H})=-0.58\end{array}$ & $\begin{array}{l}{ }^{*} \mathrm{~K}(\mathrm{CeL})=- \\
5.30\end{array}$ & $\begin{array}{l}\mathrm{K}(\mathrm{Ce}+2 \mathrm{HL} \\
=\mathrm{CeL} 2+2 \\
\mathrm{H})=-1.65\end{array}$ & $\begin{array}{l}{ }^{*} \mathrm{~K}(\mathrm{Ce} L 2)=- \\
4.55\end{array}$ \\
\hline & $\mathrm{Ce}+++$ & $\mathrm{K} 1=2.49$ & $\mathrm{~B} 2=4.06$ & & & & \\
\hline & $\mathrm{Ce}^{+++}$ & $\mathrm{K} 1=2.756$ & $\mathrm{~B} 2=4.72$ & B3 $=5.95$ & & & \\
\hline & $\mathrm{Ce}+++$ & $\mathrm{K} 1=2.33$ & $B 2=4.10$ & $\mathrm{~K} 3=1.11$ & & & \\
\hline & $\mathrm{Ce}+++$ & $\mathrm{K} 1=2.43$ & $\mathrm{~B} 2=4.11$ & B3 $=5.3$ & & & \\
\hline & $\begin{array}{l}\text { Median } \\
\text { Ce+++ }\end{array}$ & $K 1=2.76$ & $B 2=4.11$ & & & & \\
\hline & $\mathrm{Ce}++++$ & & & $\begin{array}{l}\mathrm{K}(\mathrm{CeOH}+\mathrm{L}- \\
1 \mathrm{H}=\mathrm{Ce}(\mathrm{OH}) \\
\mathrm{L}-1 \mathrm{H})=14.97\end{array}$ & & & \\
\hline & $\mathrm{Ce}++++$ & & & $\begin{array}{l}\mathrm{K}(\mathrm{Ce}+\mathrm{HL})=1 \\
.18\end{array}$ & $\begin{array}{l}\mathrm{K}(\mathrm{CeOH}+\mathrm{HL}) \\
=2.28\end{array}$ & & \\
\hline \multicolumn{5}{|l|}{ Malic acid } & & & \\
\hline & $\mathrm{Ce}+++$ & $\mathrm{K} 1=4.32$ & & $\begin{array}{l}\mathrm{K}(\mathrm{Ce}+\mathrm{HL})=2 \\
.09\end{array}$ & & & \\
\hline & $\mathrm{Ce}+++$ & $\mathrm{K} 1=4.48$ & & $\begin{array}{l}\mathrm{K}(\mathrm{Ce}+\mathrm{HL})=2 \\
.09\end{array}$ & & & \\
\hline & $\mathrm{Ce}+++$ & $\mathrm{K} 1=5.23$ & $\mathrm{~B} 2=9.98$ & & & & \\
\hline & $\mathrm{Ce}+++$ & $\mathrm{K} 1=4.10$ & & & & & \\
\hline & $\mathrm{Ce}+++$ & $\mathrm{K} 1=4.14$ & & & & & \\
\hline & $\mathrm{Ce}+++$ & $\mathrm{K} 1=4.11$ & & & & & \\
\hline & $\mathrm{Ce}^{+++}$ & $\mathrm{K} 1=5.00$ & $B 2=8.28$ & $\mathrm{~K} 3=2.75$ & & & \\
\hline & $\begin{array}{l}\text { Median } \\
\text { Ce+++ }\end{array}$ & $\mathrm{K} 1=4.32$ & B2=9.13 & & & & \\
\hline & $\mathrm{Ce}^{++++}$ & & & $\begin{array}{l}\mathrm{K}(\mathrm{CeOH}+\mathrm{L}- \\
1 \mathrm{H}=\mathrm{Ce}(\mathrm{OH}) \\
\mathrm{L}-1 \mathrm{H})=18.39\end{array}$ & & & \\
\hline & $\mathrm{Ce}++++$ & $\mathrm{K} 1=12.2$ & & & & & \\
\hline
\end{tabular}




\begin{tabular}{|c|c|c|c|c|c|}
\hline \\
\hline \multicolumn{6}{|l|}{ Citric acid } \\
\hline & $\mathrm{Ce}+++$ & $\mathrm{K} 1=6.70$ & $\mathrm{~B} 2=11.21$ & $\mathrm{~K}(\mathrm{Ce}+\mathrm{HL})=5$ & $\mathrm{~K}(\mathrm{Ce}+2 \mathrm{HL})=$ \\
\hline & & & & .10 & 7.94 \\
\hline & $\mathrm{Ce}+++$ & $\mathrm{K} 1=7.40$ & $B 2=10.40$ & $\mathrm{~K}(\mathrm{CeL}+\mathrm{HL})=$ & \\
\hline & & & & 2.40 & \\
\hline & $\mathrm{Ce}+++$ & $\mathrm{K} 1=8.82$ & $\mathrm{~B} 2=12.23$ & & \\
\hline & $\mathrm{Ce}+++$ & $\mathrm{K} 1=7.38$ & & $\mathrm{Kso}=-10.78$ & \\
\hline & $\mathrm{Ce}+++$ & & & $\mathrm{K}(\mathrm{Ce}+\mathrm{H} 2 \mathrm{~L})=$ & \\
\hline & & & & 3.2 & \\
\hline & Median & $\mathrm{K} 1=7.39$ & $B 2=11.21$ & & \\
\hline & Ce+++ & & & & \\
\hline & $\mathrm{Ce}++++$ & $\mathrm{K} 1=11.84$ & $\mathrm{~B} 2=22.32$ & & \\
\hline \multicolumn{3}{|c|}{ Glutaric acid } & & & \\
\hline & $\mathrm{Ce}+++$ & $\mathrm{K} 1=3.81$ & & & \\
\hline & $\mathrm{Ce}+++$ & $K 1=3.85$ & & & \\
\hline & $\mathrm{Ce}+++$ & $\mathrm{K} 1=3.81$ & & & \\
\hline & Median & $K 1=3.81$ & & & \\
\hline & Ce+++ & & & & \\
\hline \multicolumn{4}{|c|}{ Succinic acid } & & \\
\hline & $\mathrm{Ce}+++$ & $\mathrm{K} 1=3.86$ & & & \\
\hline & $\mathrm{Ce}+++$ & $\mathrm{K} 1=3.90$ & & & \\
\hline & $\mathrm{Ce}+++$ & $\mathrm{K} 1=3.86$ & & & \\
\hline & $\mathrm{Ce}+++$ & $\mathrm{K} 1=2.18$ & $B 2=4.40$ & & \\
\hline & Median & $\mathrm{K} 1=3.86$ & & & \\
\hline & $\mathrm{Ce}+++$ & & & & \\
\hline \multicolumn{3}{|c|}{ Adipic acid - no entry } & & & \\
\hline \multicolumn{3}{|c|}{ Hydroxybutyric acid - no entry } & & & \\
\hline \multicolumn{3}{|c|}{ Pimelic acid - no entry } & & & \\
\hline \multicolumn{3}{|c|}{ Tricarballylic acid - no entry } & & & \\
\hline
\end{tabular}




\section{Supplemental Material: Carboxylic Acids Accelerate Acidic Environment-}

Mediated Nanoceria Dissolution

Figure S1. Nanoceria dissolution half-life (ranked from 1 = shortest to 10 longest) plotted against agglomerate size (ranked from $1=$ smallest to 10 largest) in the presence of the carboxylic acids. The correlation coefficient $\left(\mathrm{r}^{2}\right)$ is 0.73 .

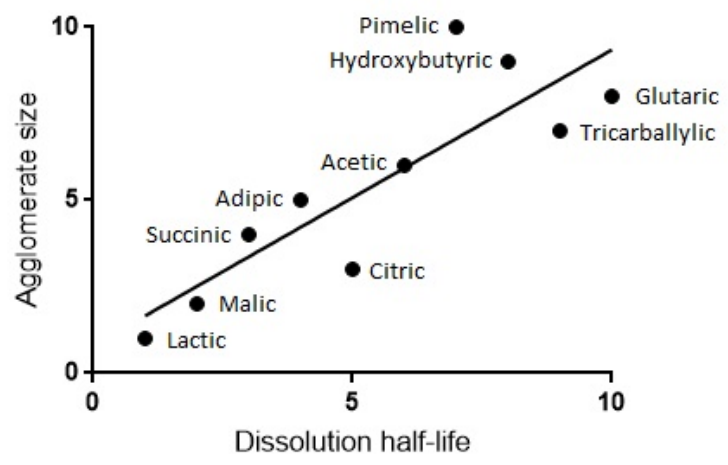

